RICARDO DUARTE SILVA

\title{
Avaliação dos distúrbios ácido-base e eletrolíticos de cães com cetose e
} cetoacidose diabética

Tese apresentada ao Programa de Pós-graduação em Clínica Veterinária da Faculdade de Medicina Veterinária e Zootecnia da Universidade de São Paulo para obtenção do título de Doutor em Medicina Veterinária

\section{Departamento:}

Clínica Médica

Área de concentração:

Clínica Veterinária

\section{Orientador:}

Profa. Dra. Márcia Mery Kogika

São Paulo 
Autorizo a reprodução parcial ou total desta obra, para fins acadêmicos, desde que citada a fonte.

DADOS INTERNACIONAIS DE CATALOGAÇÃO-NA-PUBLICAÇÃO

(Biblioteca da Faculdade de Medicina Veterinária e Zootecnia da Universidade de São Paulo)

Silva, Ricardo Duarte

Avaliação dos distúrbios ácido-base e eletrolíticos de cães com cetose e cetoacidose diabética / Ricardo Duarte Silva. - São Paulo : R. D. Silva, 2006.

$61 \mathrm{f}$ : : il.

Tese (doutorado) - Universidade de São Paulo. Faculdade de Medicina Veterinária e Zootecnia. Departamento de Clínica Médica, 2006.

Programa de Pós-graduação: Clínica Veterinária.

Área de concentração: Clínica Veterinária.

Orientadora: Profa. Dra. Márcia Mery Kogika.

1. Diabetes Mellitus. 2. Cetoacidose diabética. 3. Cães. 4. Desequilíbrio ácido-básico. 5. Eletrólitos. I. Título. 


\section{UNIVERSIDADE DE SÃO PAULO \\ Faculdade de Medicina Veterinária e Źootecnia \\ Cidade Universitária "Armando de Salles Oliveira" \\ Comissão Bioética \\ CERTIFICADO}

Certificamos que o Projeto intitulado "Avaliação dos padrões dos distúrbios ácido-base de cães com cetoacidose diabética", Protocolo n³65/2003, utilizando 80 cães, sob a responsabilidade da Prof ${ }^{\mathrm{a}} \mathrm{Dr}^{\mathrm{a}}$ Márcia Mery Kogika, está de acordo com os princípios éticos de experimentação animal da Comissão de Bioética da Faculdade de Medicina Veterinária e Zootecnia da Universidade, de São Paulo e foi aprovado pela referida Comissão, em sessão do dia 10 de março de 2004.

(We certify that the Research "Evaluation of plasma acid-base patterns in dogs with diabetic ketoacidosis" protocol number 365/2003, utilizing 80 dogs, under the responsibility of Prof. Dr. Márcia Mery Kogika, agree with Ethical Principles in Animal Research adopted by Bioethic Commission of the Faculty of Veterinary Medicine and Zootechny of University of São Paulo and was approved in 03/10/2004 meeting.

São Paulo, 10 de março de 2004

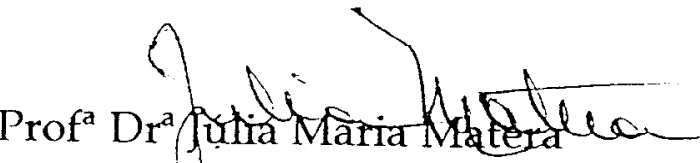

Presidente da Comissão de Bioética

FMVZ/USP 


\section{FOLHA DE AVALIAÇÃO}

Nome: SILVA, Ricardo Duarte

Título: Avaliação dos distúrbios ácido-base e eletrolíticos de cães com cetose e cetoacidose diabética

Tese apresentada ao Programa de Pós-graduação em Clínica Veterinária da Faculdade de Medicina Veterinária e Zootecnia da Universidade de São Paulo para obtenção do título de Doutor em Medicina Veterinária

Data: /2006

Banca Examinadora

Prof. Dr. Instituição:

Assinatura: Julgamento:

Prof. Dr. Instituição:

Assinatura: Julgamento:

Prof. Dr. Instituição:

Assinatura: Julgamento:

Prof. Dr. Instituição:

Assinatura: Julgamento:

Prof. Dr. Instituição:

Assinatura: Julgamento: 


\section{DEDICATÓRIA}

Esse trabalho é dedicado à minha família, meus pais Luiz e Neisme, meu irmão Gilberto e minha amada Denise.

À minha orientadora,

\section{Márcia Mery Kogika,}

que, com seu entusiasmo e paciência, me ensinou apreciar a pesquisa clínica, como um modo interessante de passar a vida. 


\section{AGRADECIMENTOS}

Ao Prof. Dr. Cássio Xavier de Mendonça Jr, Diretor da Faculdade de Medicina Veterinária e Zootecnia da Universidade de São Paulo.

A todos médicos veterinários, residentes e funcionários do Departamento de Clínica Médica da Faculdade de Medicina Veterinária e Zootecnia/Hospital Veterinário da Universidade de São Paulo, sem os quais não seria possível a realização desse trabalho.

À Fundação de Amparo a Pesquisa do estado de São Paulo (FAPESP) pelo suporte financeiro a esse projeto (processo 03/14127-0)

Ao Prof. Dr. Carlos Eduardo Larsson, coordenador do curso de pós-graduação em Clínica Veterinária, pelo apoio.

À Prof Dra. Maria Helena Matiko Akao Larsson chefe do Laboratório Clínico do Departamento de Clínica Médica/HOVET-FMVZ-USP e à Regina Mieko Sakata Mirandola pelo apoio no início desse projeto.

Aos professores Archivaldo Reche Jr, André Luis do Valle de Zoppa, Carlos Eduardo Larsson, Clair Motos de Oliveira, Denise Tabacchi Fantoni, Enrico Lippi Ortolani, Fernando José Benesi, Francisco J.H. Blazquez, Franklin de Almeida Sterman, Julia Maria Matera, Lilian Gregory, Luis Claudio L.C. da Silva, Márcia Marques Jericó, Maria Helena M.A. Larsson, Mitika K. Hagiwara, Raquel Yvonne Arantes Baccarin, Ricardo Coutinho do Amaral, Silvia Regina Ricci Lucas, Silvia Renata Gaido Cortopassi, e Wilson Roberto Fernandes, pela inestimável contribuição à minha trajetória profissional e pessoal.

Ao coordenador do curso de Veterinária da UNIPINHAL, Roberto Mendes Porto Filho e ao coordenador administrativo do Hospital Veterinário Celso Leite Villela e aos Médicos Veterinários Carlos Alberto Geraldo Jr e Paulo Roberto Martin, que possibilitaram a conclusão do doutorado.

Aos amigos Márcio Lustoza e Luciano Giovaninni, pela generosa colaboração nos relatórios.

Aos amigos Ana Claudia Balda, Alessandra Vargas, Alexandre Merlo, Ana Carolina Brandão de C. Fonseca Pinto, Carlos Alberto Geraldo Jr, Cláudia Brito, Edna Santana dos Santos, Fabrício Brasil, João de Azevedo Mattos, José Fernando Ibanês, Josué Lolli Junior, Juliana Doretto, Karina Yasbek, Leonardo Pinto Brandão, Luciana Domingos, Marcelo Faustino, Maria Adriana Machado Lobo e Silva, Maria Alessandra del Barrio, Maria Helena da Silva Pelissari, Mary Otsuka, Maurício Marquesi, Paola Lazaretti, Patrícia Popak, Paulo Roberto Martin, Rafael Costa Jorge, Rafael Parra Lessa, Raquel Niero, Rita de Cássia Carmona Castro, Roberto Mendes Porto Filho, Rodrigo Martins Soares, Ronaldo Jun Yamato, Samantha Myashiro, Sílvia Cortopassi, e Viviani de Marco e também aos meus sogros e cunhados.

A todos os proprietários dos cães diabéticos, por me permitirem compartilhar de seu carinho e dedicação.

Ao meu grande amigo Wagner Sato Ushikoshi. 


\section{Aos colaboradores:}

Os médicos veterinários do Departamento de Clínica Médica/HOVET-FMVZ-USP, Bruna Maria P. Coelho, Denise Maria Nunes Simões, Júlia Habu Ikesaki, Khadine Kazue Kanayama, Maria Luisa Franchini, Mary Otsuka e Paula Rumy Monteiro Strefezzi

Aos auxiliares do Serviço de Clínica Médica e Pronto Atendimento do Departamento de Clínica Médica/HOVET-FMVZ-USP, Antonio Carlos Malaquias, Carlito dos Santos Belau, Geraldo Natalino Tezzi, Gilberto Pereira da Cruz e Milton Gregório dos Santos.

Aos funcionários do Laboratório Clínico do HOVET-FMVZ/USP, Clara Satsuki Mori, Creide Donizete Costa, Edna Santana dos Santos, Marli Elizabete Ferreira de Castro e Maria Helena da Silva Pelissari.

Às secretárias da pós-graduação Adelaide Borges e Harumi Shiraishi.

À Maria de Fátima dos Santos e à Rosa Maria Zani da Biblioteca da FMVZ-USP.

À Ting Hui Ching, pela análise estatística. 


\section{RESUMO}

SILVA, R. D. Avaliação dos distúrbios ácido-base e eletrolíticos de cães com cetose e cetoacidose diabética. [Evaluation of acid-base and electrolyte disturbances in dogs with diabetic ketosis and ketoacidosis]. 2006. 61 f. Tese (Doutorado em Medicina Veterinária) Faculdade de Medicina Veterinária e Zootecnia, Universidade de São Paulo, São Paulo, 2006.

A cetoacidose diabética (CAD) é uma das complicações mais graves do diabetes mellitus (DM) em pequenos animais. A CAD é uma emergência médica caracterizada por alterações metabólicas extremas, incluindo hiperglicemia, acidose metabólica, cetonemia, desidratação e perda de eletrólitos. Embora seja um distúrbio comum e de alta mortalidade, os padrões dos distúrbios ácido-base de cães com CAD ainda não foram avaliados objetivamente. Muitas das assunções sobre a CAD em cães são generalizadas com base em dados de pacientes humanos e estudos experimentais em cães. O objetivo do presente estudo foi descrever os distúrbios ácido-base e eletrolíticos de cães com CAD e cetose diabética (CD) e caracterizá-los segundo a freqüência de ocorrência, adequação dos mecanismos de compensação e ocorrência de distúrbios mistos. Foram avaliados 40 cães diabéticos (22 animais recém diagnosticados e 18 cães em tratamento com insulina) atendidos apresentando cetonúria e hiperglicemia (>250 mg/dL). De acordo com critérios clínicos, esses cães foram distribuídos em dois subgrupos: $(\mathrm{CAD}, \mathrm{n}=22$ e $\mathrm{CD} \mathrm{n}=18)$ e foram determinados o $\mathrm{pH}$ e a hemogasometria arteriais e eletrólitos plasmáticos (sódio, cloro, potássio, cálcio ionizado) e o magnésio total e o fósforo inorgânico séricos. As alterações do equilíbrio ácido-base foram avaliadas sistematicamente pelo método de Van Slyke-Henderson-Hasselbalch. Os resultados foram comparados com os obtidos a partir de 37 cães clinicamente hígidos. Com relação aos distúrbios ácido-base, a acidose metabólica foi o mais comumente identificado $(n=27)$. A maior parte dos animais apresentava acidose normoclorêmica. A acidose hiperclorêmica foi observada em sete pacientes. Dos cães com acidose metabólica, 15 apresentavam alcalose respiratória concomitante. A distribuição dos valores de eletrólitos foi diferente entre o grupo 
de estudo e o controle, com exceção do magnésio. Não houve diferença na distribuição dos valores dos eletrólitos entre os subgrupos, com exceção do potássio plasmático. A hiponatremia e a hipocloremia foram os distúrbios eletrolíticos mais comumente observados nos 40 cães com DM. A hipocalemia ocorreu com maior freqüência no subgrupo CAD e a hipercalemia no subgrupo CD. Os valores do fósforo inorgânico sérico foram semelhantes entre os subgrupos de estudo. A hiperfosfatemia foi comum em ambos os subgrupos e nenhum paciente apresentou hipofosfatemia. A hipermagnesemia foi observada em sete pacientes com CAD e em apenas um com CD. A maior parte dos pacientes tinha hipocalcemia por ocasião do atendimento inicial. Distúrbios ácido-base mistos, principalmente a acidose metabólica normoclorêmica associada a alcalose respiratória são comuns em cães com cetose ou cetoacidose diabética, assim como distúrbios eletrolíticos como hiponatremia, a hipocloremia e hipocalemia e hiperfosfatemia.

Palavras-chave: Cães. Diabetes Mellitus. Cetoacidose diabética. Desequilíbrio ácido-base. Eletrólitos. 


\begin{abstract}
SILVA, R. D. Evaluation of acid-base and electrolyte disturbances in dogs with diabetic ketosis and ketoacidosis. [Avaliação dos distúrbios ácido-base e eletrolíticos de cães com cetose e cetoacidose diabética]. 2006. 61 f. Tese (Doutorado em Medicina Veterinária) Faculdade de Medicina Veterinária e Zootecnia, Universidade de São Paulo, São Paulo, 2006.
\end{abstract}

Diabetic ketoacidosis (DKA) is one of the most serious complications of diabetes mellitus (DM) in small animals. DKA is a medical emergency characterized by extreme metabolic abnormalities, including hyperglycemia, metabolic acidosis, ketonemia, dehydration, and electrolyte losses. Despite it is a common disorder and with high mortality, the patterns of the acid-base disturbances in dogs with DKA were not evaluated objectively. Many of the assumptions about DKA in dogs are derived from studies in human beings and experimental studies in dogs. The objective of the present study was to describe the acid-base and electrolytic disturbances in dogs with DKA and diabetic ketosis (DK) according to their frequency, adequacy of the compensatory mechanisms e occurrence of mixed disturbances. Forty dogs with DM (22 with new onset diabetes and 18 insulin-treated dogs) with ketonuria and hyperglycemia ( $>250 \mathrm{mg} / \mathrm{dL}$ ) were enrolled. On the basis of clinical criteria, the dogs were assigned to one of two subgroups: (DKA, $n=22$ e DK $n=18)$. Arterial blood gases and plasma electrolytes (sodium, chloride, potassium and, ionized calcium), and serum total magnesium and inorganic phosphorus were determined in all dogs. The acid base abnormalities were evaluated systematically by the Van Slyke-Henderson-Hasselbalch method and the results compared to those obtained from 37 healthy dogs (control group). Metabolic acidosis was the most common acid-base disorder identified $(n=27)$ and most of the dogs had normochloremic acidosis. Hyperchloremic acidosis was observed in seven patients. Fifteen of the dogs with metabolic acidosis had coexisting respiratory alkalosis. The distribuition of the electrolytes values was different between the study group and the control group, with the exception of serum magnesium. The distribution of the electrolytes values was 
similar between the subgroups, with the exception of plasma potassium. Hyponatremia and hypochloremia were the most common observed electrolyte abnormalities showed in dogs with DK or DKA. Hypokalemia occurred more frequently in dogs with DKA and hyperkalemia in dogs with DK. Serum inorganic phosphorus values were similar between the subgroups. Hyperphosphatemia was a common finding and hypophosphatemia was not observed. Hypermagnesemia was detected in seven patients with DKA and in only one with DK. Most of the dogs were hypocalcemic on admission. Mixed acid-base disorders, mainly metabolic normochloremic acidosis with coexisting respiratory alkalosis are common in dogs with diabetic ketosis or ketoacidosis and electrolytic disturbances, mostly hyponatremia, hypochloremia, hypokalemia, and hyperphosphatemia, were also common.

Key-words: Dogs. Diabetes Mellitus. Diabetic Ketoacidosis. Acid-Base Imbalance. Electrolytes. 


\section{LISTA DE APÊNDICES}

APÊNDICE A - Características dos cães incluídos no subgrupo cetoacidose diabética (CAD)

APÊNDICE B - Características dos cães incluídos no subgrupo cetose diabética (CD).

APÊNDICE C - Avaliação da homocedastidade e diferenças entre os subgrupos de estudo por análise de variância (ANOVA) e pelo teste não-paramétrico de MannWhitney das variáveis do estudo.

APÊNDICE D - Valores da determinação do pH, hemogasometria, déficit de base, temperatura corpórea, eletrólitos e bioquímica sérica dos cães incluídos no subgrupo cetoacidose diabética (CAD).

APÊNDICE E - Valores da determinação do pH, hemogasometria, déficit de base, temperatura corpórea, eletrólitos e bioquímica sérica dos cães incluídos no subgrupo cetose diabética (CD)

APÊNDICE F - Características e valores da hemogasometria dos cães clinicamente hígidos incluídos no grupo controle..

APÊNDICE G - Valores da determinação dos eletrólitos plasmáticos e bioquímica sérica dos cães clinicamente hígidos incluídos no grupo controle. 


\section{LISTA DE GRÁFICOS}

Gráfico 1 - Exemplos teóricos da distribuição dos eletrólitos plasmáticos de $(A)$ um cão normal; (B) um cão com acidose normoclorêmica (aumento do anion gap); (C) um cão com acidose hiperclorêmica e $(D)$ um cão com acidose hiperclorêmica e aumento do anion gap concomitante. Nesse último, apesar da concentração plasmática do cloro $\left(\mathrm{Cl}^{-}\right)$ser normal, ela é excessiva em relação à diminuição da concentração de sódio $\left(\mathrm{Na}^{+}\right)$. A eletroneutralidade é mantida em todos os casos, i.e., a somatória dos cátions é igual a dos ânions. (Modificado de DIBARTOLA, 1999a).

Gráfico 2 - Intervalo interquartílico (caixas), mediana (traços horizontais) e variação (traços verticais) dos valores de $(A) \mathrm{pH}$ sangüíneo; $(B)$ bicarbonato plasmático; (C) pressão parcial de dióxido de carbono e (D) anion gap dos cães dos subgrupos cetose diabética (CD) e cetoacidose diabética (CAD). Os quadrados tracejados representam os intervalos de referência e, os círculos, os valores extremos, São Paulo - mar 2003 - ago 2005

Gráfico 3 - Relação entre os valores da pressão parcial de $\mathrm{CO}_{2}\left(\mathrm{PCO}_{2}\right)$ e bicarbonato ([HCO3]) plasmáticos dos cães com acidose metabólica do grupo de estudo $(\mathrm{n}=27)$. As linhas diagonais azuis representam o intervalo da $\mathrm{PCO}_{2}$ considerado apropriado para a $\left[\mathrm{HCO}_{3}{ }^{-}\right]$, São Paulo - mar 2003 - ago 2005.

Gráfico 4 - Intervalo interquartílico (caixas), mediana (traços horizontais) e variação (traços verticais) dos valores de (A) sódio plasmático; (B) cloro plasmático e (C) potássio plasmático dos cães dos subgrupos cetose diabética (CD) e cetoacidose diabética (CAD). Os quadrados tracejados representam os intervalos de referência e, os círculos, os valores extremos, São Paulo - mar 2003 - ago 2005

Gráfico 5 - Intervalo interquartílico (caixas) mediana, (traços horizontais) e variação (traços verticais) dos valores de (A) fósforo inorgânico sérico; (B) cálcio ionizado plasmático e $(\mathrm{C})$ magnésio total sérico dos cães dos subgrupos cetose diabética (CD) e cetoacidose diabética (CAD). Os quadrados tracejados representam os intervalos de referência e, os círculos, os valores extremos, São Paulo mar 2003 ago 2005 


\section{LISTA DE TABELAS}

Tabela 1 - Características dos cães diabéticos dos subgrupos cetoacidose diabética (CAD) e cetose diabética (CD) - São Paulo - mar 2003 - ago 2005.

Tabela 2 - Manifestações clínicas dos cães diabéticos do grupo de estudo e seus subgrupos cetoacidose diabética (CAD) e cetose diabética (CD) - São Paulo - mar 2003 ago 2005 .

Tabela 3 - Valores da mediana, mínimo e máximo de $\mathrm{pH}$ sangüíneo, pressão dos gases sangüíneos, déficit de base e anion gap dos cães dos subgrupos cetoacidose diabética (CAD) e cetose diabética (CD), São Paulo - mar 2003 - ago 2005.

Tabela 4 - Valores da mediana, mínimo e máximo dos eletrólitos dos cães dos subgrupos cetoacidose diabética (CAD) e cetose diabética (CD), São Paulo - mar 2003 ago 2005 . 


\section{LISTA DE ABREVIATURAS}

AG: anion gap;

$\mathrm{BE}$ : déficit de base;

$\mathrm{Ca}^{2+}:$ cálcio ionizado plasmático;

CAD: cetoacidose diabética;

CD: cetose diabética;

$\mathrm{Cl}^{-}$: Cloro plasmático;

DM: diabetes mellitus;

F: fêmea;

FC: fêmea castrada;

HAC: hiperadrenocorticismo;

$\left[\mathrm{HCO}_{3}\right]$ : concentração plasmática do bicarbonato;

$\beta$-HOB: $\beta$-hidroxibutirato sérico.

$\mathrm{K}^{+}$: potássio plasmático;

M: macho

Mg: magnésio total sérico;

$\mathrm{Na}^{+}$: sódio plasmático;

$\mathrm{PCO}_{2}$ : pressão parcial de dióxido de carbono;

$\mathrm{PO}_{2}$ : pressão parcial de oxigênio;

Pi: fósforo inorgânico sérico;

$\mathrm{SO}_{2}$ : saturação sangüínea de oxigênio. 


\begin{tabular}{|c|c|}
\hline 1 & INTRODUÇÃO \\
\hline 2 & JUSTIFICATIVA \\
\hline 3 & OBJETIVOS \\
\hline 3 & MATERIAIS E MÉTODOS .......... \\
\hline 3.1 & ANIMAIS ..... \\
\hline 3.2 & MÉTODOS......... \\
\hline 3.3 & AVALIAÇÃO DO EQUILÍBRIO ÁCIDO-BASE \\
\hline 3.1 & ANÁLISE ESTATÍSTICA ............................... \\
\hline 4 & RESULTADOS \\
\hline 4.1 & 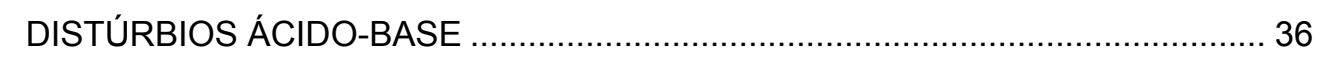 \\
\hline 4.2 & 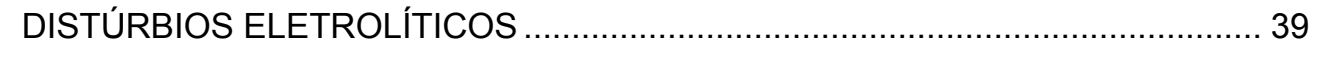 \\
\hline 5 & DISCUSSÃO \\
\hline 5.1 & 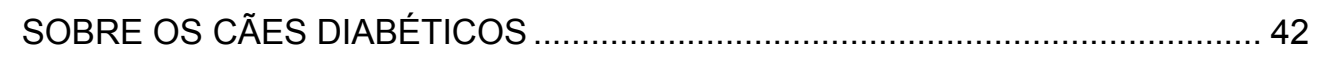 \\
\hline 5.2 & SOBRE OS DISTÚRBIOS ÁCIDO-BASE ..... \\
\hline 5.3 & SOBRE OS DISTÚRBIOS ELETROLÍTICOS ......... \\
\hline 5.4 & DAS LIMITAÇÕES DO ESTUDO ....... \\
\hline 6 & CONCLUSÕES ... \\
\hline & REFERÊNCIAS.. \\
\hline & 'F̂ \\
\hline
\end{tabular}




\section{Introdução}

O diabetes mellitus (DM) é uma das endocrinopatias mais comuns na clínica de pequenos animais. A doença caracteriza-se pela hiperglicemia, decorrente da deficiência de secreção de insulina ou da incapacidade de a insulina exercer seus efeitos metabólicos (AMERICAN DIABETES ASSOCIATION, 1997). A causa do DM em cães ainda não foi completamente elucidada, mas sem dúvida é multifatorial. Estão envolvidos na etiologia da doença, predisposição genética, distúrbios imune-mediados, pancreatite e fatores de resistência à insulina, como obesidade, hipercortisolismo e infecções (FELDMAN e NELSON, 2004a). A prevalência hospitalar do DM em cães varia de 0,2 a 1\% (HESS et al., 2000; MARMOR et al., 1982).

Uma das complicações mais graves do DM em pequenos animais é a cetoacidose diabética (CAD) (FELDMAN e NELSON, 2004b). A CAD é uma emergência médica caracterizada por alterações metabólicas extremas, incluindo hiperglicemia, acidose metabólica, cetonemia, desidratação e perda de eletrólitos. A CAD ocorre quando há uma deficiência de insulina combinada a um excesso de hormônios hiperglicemiantes (catecolaminas, glucagon, cortisol e hormônio do crescimento) (FELDMAN e NELSON, 2004b; KITABCHI et al., 2001). A mortalidade decorrente da CAD em cães é de aproximadamente 30\% a 40\% (FELDMAN e NELSON, 2004b; MACINTIRE, 1993).

Os achados clínicos da CAD em cães incluem: poliúria, polidipsia, perda de peso, letargia, depressão, anorexia, emese, desidratação, dor abdominal, taquipnéia e hálito cetônico (BRUYETTE, 1997; FELDMAN e NELSON, 2004b). O planejamento diagnóstico e terapêutico deve ser voltado ao controle da CAD e de suas complicações, com cuidadosa atenção às suas conseqüências metabólicas e ao escrutínio de seus fatores precipitantes (CRENSHAW e NICHOLS, 1995). A terapia adequada implica monitoração clínica e laboratorial intensiva do animal e reversão gradual dos distúrbios metabólicos (BRUYETTE, 
1997; FELDMAN e NELSON, 2004b). O período necessário para remissão da cetonúria e estabilização do paciente cetoacidótico depende do quadro clínico inicial (LINARES et al., 1996). Em um estudo clínico da CAD em cães, o tempo de hospitalização necessário para correção da acidose e resolução da cetonúria variou de seis horas a 72 horas (MACINTIRE, 1993).

A deficiência de insulina, que é o evento desencadeador da cetogênese em pacientes diabéticos, pode ser absoluta, quando as concentrações plasmáticas de insulina são baixas ou não detectáveis (e.g., DM não diagnosticado, omissão da insulinoterapia adequada). Entretanto, alguns animais podem apresentar concentrações de insulina similares às observadas em indivíduos não diabéticos, mas inadequadas (hipoinsulinemia relativa) para a gravidade do quadro de hiperglicemia (FELDMAN e NELSON, 2004b). A deficiência relativa de insulina também pode ocorrer em animais diabéticos recebendo a dose adequada de insulina, quando da presença de fatores de resistência à insulina como, por exemplo, processos infecciosos, diestro e hiperadrenocorticismo. Essas condições, freqüentemente associadas à CAD, são fatores reconhecidos de resistência insulínica e podem descompensar o animal diabético por aumentar as concentrações circulantes dos hormônios hiperglicemiantes (BRUYETTE, 1997).

$\mathrm{Na}$ ausência de insulina efetiva, ocorre a quebra dos triglicérides em ácidos graxos livres e glicerol (lipólise). O glicerol fornece o esqueleto carbônico para síntese de glicose no processo denominado gliconeogênese, que ocorre no fígado e é especificamente estimulado pelo aumento das concentrações séricas do glucagon e pela hipoinsulinemia. O catabolismo protéico e a redução da síntese de proteínas, também resultantes do aumento da concentração sérica do glucagon e da diminuição da concentração da insulina, promovem o aumento dos aminoácidos circulantes, que servem como substrato para a gliconeogênese. Outros hormônios contra-reguladores contribuem para a fisiopatogenia da CAD, primariamente, por 
promoverem antagonismo da ação da insulina em tecidos periféricos e, também, por estimularem a conversão do glicogênio em glicose (glicogenólise). Atribui-se, assim, o desenvolvimento da hiperglicemia ao aumento da gliconeogênese e glicogenólise hepáticas e ao uso inadequado da glicose pelos tecidos periféricos (FELDMAN e NELSON, 2004b; KITABCHI et al., 2001).

A lipólise é mediada pela lipase-hormônio-sensível, cuja ação é também especificamente estimulada pelo aumento na relação glucagon:insulina (LAFFEL, 1999). Os ácidos graxos livres produzidos pela lipólise são utilizados nos tecidos periféricos como substrato de energia e, na dependência de sua concentração plasmática, também são assimilados pelo fígado, onde são convertidos em acil-CoA, que é oxidada, formando a acetilCoA. Em condições de hipoinsulinemia a acetil-CoA é condensada à acetoacetil-CoA, formando o ácido acetoacético que, na presença do $\mathrm{NADH}$, é reduzido a ácido $\beta$-hidroxibutírico. A acetona é formada a partir da descarboxilação espontânea do ácido acetoacético (LAFFEL, 1999). Em pH fisiológico, os ácidos acetoacético e $\beta$-hidroxibutírico se dissociam e os íons hidrogênio resultantes são tamponados, principalmente pelo bicarbonato plasmático. Entretanto, a carga de íons hidrogênio gerada durante a produção patológica dos corpos cetônicos, como ocorre na $\mathrm{CAD}$, rapidamente esgota a capacidade dos sistemas de tamponamento do sangue, resultando em cetose e acidose metabólica (DIBARTOLA, 1999a). A cetonemia contribui, ainda, para o agravamento do quadro clínico do paciente, pois os corpos cetônicos estimulam os centros quimiorreceptores nervosos, induzindo náusea, anorexia, êmese e dor abdominal (BELL e ALELE, 1997).

A hiperglicemia e a cetose determinam o desenvolvimento de diurese osmótica, devido a glicosúria e eliminação de ânions cetônicos e de eletrólitos (potássio, sódio, cloro e fósforo) pela urina (FELDMAN e NELSON, 2004b). A perda de água pela urina e as perdas adicionais de líquidos por êmese e hiperventilação contribuem para o desenvolvimento da 
desidratação. A diminuição do volume intravascular reduz a taxa de filtração glomerular, favorecendo o acúmulo de corpos cetônicos e glicose no sangue. A hipovolemia grave, associada à acidose metabólica e a doenças concorrentes, contribui para o desenvolvimento de insuficiência renal aguda e choque durante a progressão da CAD (FELDMAN e NELSON, 2004b; KITABCHI et al., 2001).

Para o diagnóstico e avaliação inicial do paciente com CAD recomenda-se a determinação da hemogasometria, do pH sangüíneo, do bicarbonato plasmático e o cálculo do anion gap (KITABCHI et al., 2001). A avaliação do estado ácido-base do paciente é realizada pelo método de Van Slyke, que é baseado na equação de Henderson-Hasselbalch:

$$
\mathrm{pH}=6,1+\log \frac{\left[\mathrm{HCO}_{3}^{-}\right]}{0,03 \cdot \mathrm{PCO}_{2}}
$$

Por essa abordagem, as alterações na concentração dos íons hidrogênio (expressa pelo pH) são determinadas pelas interações entre a pressão parcial de dióxido de carbono $\left(\mathrm{PCO}_{2}\right) \mathrm{e}$ a concentração plasmática do bicarbonato $\left(\left[\mathrm{HCO}_{3}\right]\right)$. As alterações na $\left[\mathrm{HCO}_{3}\right]$ (o componente metabólico) e na $\mathrm{PCO}_{2}$ (o componente respiratório) desencadeiam os quatro distúrbios ácidobase primários: acidose metabólica, acidose respiratória, alcalose metabólica e alcalose respiratória (HALPERIN; GOLDSTEIN, 1999).

Para cada distúrbio existe um mecanismo compensatório esperado. A acidose metabólica, por exemplo, deve desencadear hipocapnia e alcalose respiratória. A partir dos mecanismos compensatórios previstos, é possível determinar se o distúrbio é simples, limitado à alteração primária e ao mecanismo compensatório secundário apropriado, ou misto, i.e., dois ou três distúrbios concorrentes (DIBARTOLA, 1999b). A variação esperada da resposta compensatória aos distúrbios ácido-base em cães é baseada em estudos experimentais (DE MORAIS; DIBARTOLA, 1991). 
Para avaliação dos distúrbios metabólicos recomenda-se, ainda, a determinação do anion gap e do déficit ou excesso de base (base excess [BE]). O anion gap (AG) é uma estimativa da concentração de ânions no plasma que não são rotineiramente mensurados (e.g., corpos cetônicos, lactato, fosfatos e sulfatos). O AG é calculado subtraindo-se os principais cátions (sódio e potássio) dos principais ânions (cloro e $\mathrm{HCO}_{3}{ }^{-}$) (KITABCHI et al., 2001). O cálculo do AG é recomendado para discriminação do tipo de acidose metabólica que acomete o paciente. A diminuição da $\left[\mathrm{HCO}_{3}^{-}\right]$, associada ao aumento do $\mathrm{AG}$, é sugestiva de acidose normoclorêmica primária (acúmulo de ácidos orgânicos). A acidose metabólica, associada a um valor normal de AG, é sugestiva de acidose hiperclorêmica primária (decorrente do acúmulo de cloro). Quadros mistos de hipercloremia e aumento do anion gap também podem ocorrer (Gráfico 1).

Normal

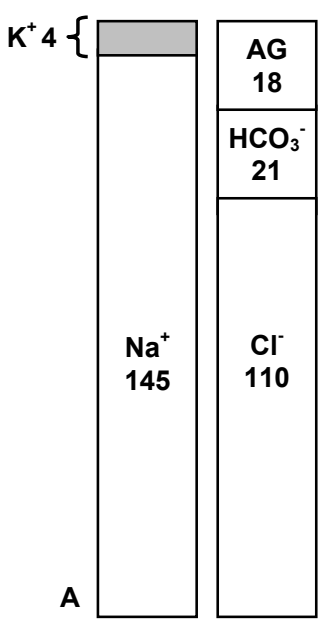

Acidose normoclorêmica pura

B
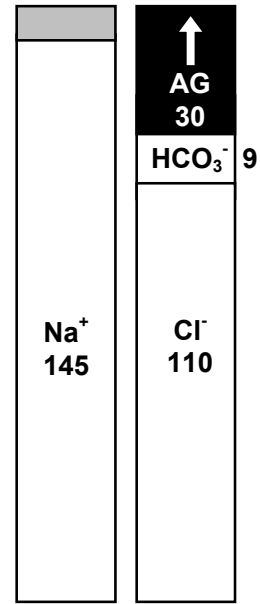

Acidose hiperclorêmica pura

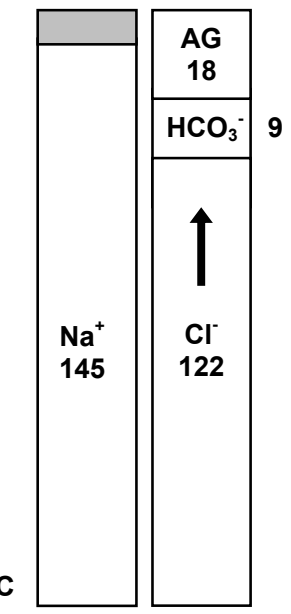

Acidose metabólica mista

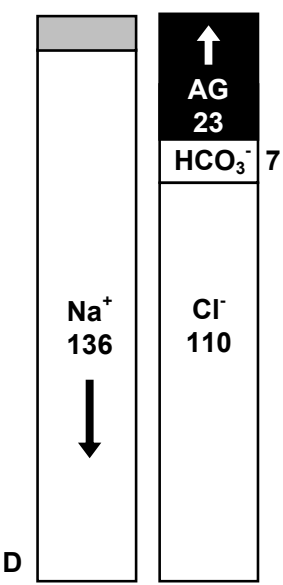

Gráfico 1 - Exemplos teóricos da distribuição dos eletrólitos plasmáticos de $(A)$ um cão normal; (B) um cão com acidose normoclorêmica (aumento do anion gap); (C) um cão com acidose hiperclorêmica e $(D)$ um cão com acidose hiperclorêmica e aumento do anion gap concomitante. Nesse último, apesar da concentração plasmática do cloro $\left(\mathrm{Cl}^{-}\right)$ser normal, ela é excessiva em relação à diminuição da concentração de sódio $\left(\mathrm{Na}^{+}\right)$. A eletroneutralidade é mantida em todos os casos, i.e., a somatória dos cátions é igual a dos ânions. (Modificado de DIBARTOLA, 1999a) 
O BE é a quantidade (em mmol/L) de ácido ou base necessária para titular um litro de sangue a um $\mathrm{pH}$ igual a 7,4 , em condições de temperatura e $\mathrm{PCO}_{2}$ constantes $\left(40^{\circ} \mathrm{C}\right.$ e $40 \mathrm{~mm} \mathrm{Hg}$, respectivamente). O BE é calculado por meio do nomograma de SiggaardAndersen, a partir dos valores mensurados de $\mathrm{pH}, \mathrm{PCO}_{2}$ e hemoglobina. $\mathrm{O}$ aumento do valor do BE é sugestivo de um componente metabólico (não respiratório) importante para alcalose e a diminuição é sugestiva de um componente metabólico para a acidose (DIBARTOLA, 1999b).

Para o diagnóstico e a avaliação do quadro de CAD em seres humanos recomenda-se a avaliação da hemogasometria arterial, para confirmar a presença de acidemia (pH do sangue arterial $<7,30)$ ou acidose $\left(\left[\mathrm{HCO}_{3}\right]<15 \mathrm{mEq} / \mathrm{L}\right)$, associada(s) à presença de cetonemia ou cetonúria (AMERICAN DIABETES ASSOCIATION, 2004). Critérios específicos para o diagnóstico da CAD em pequenos animais variam na literatura veterinária (BRUYETTE, 1997; CRENSHAW e NICHOLS, 1995; FELDMAN e NELSON, 2004b; MACINTIRE, 1993).

Embora esses critérios sirvam bem para propósito de pesquisa, são um tanto restritivos na rotina clínica. Muitos dos pacientes admitidos com diagnóstico de CAD têm acidose metabólica discreta, apesar da elevação das concentrações da glicose e do $\beta$-hidroxibutirato séricos. A maioria desses pacientes está alerta, é capaz de tolerar hidratação oral e pode ser tratada em ambulatório. Pacientes com CAD moderada a grave (concentração plasmática de $\left[\mathrm{HCO}_{3}{ }^{-}\right]<15 \mathrm{mEq} / \mathrm{L}$ ou $\mathrm{pH}$ sangüíneo $\left.<7,25\right)$ têm maior probabilidade de desenvolver complicações do que aqueles com CAD discreta e precisam de tratamento intensivo (KITABCHI et al., 2001).

Um quadro semelhante ocorre em cães com diabetes. Cães com CAD necessitam de tratamento intensivo e monitoração laboratorial freqüente. A distinção do diabético com CAD, daquele portador de "cetose diabética" é essencial para a abordagem clínica correta. O 
diagnóstico presuntivo de cetose diabética é reservado ao animal que, apesar de aparentemente sadio, apresenta corpos cetônicos na urina. Manifestações de doença sistêmica -outros que não os atribuídos ao diabetes não tratado (e.g., poliúria, polidipsia, polifagia, emagrecimento)- estão ausentes e a acidose metabólica é discreta. Esses animais, também chamados "cetoacidóticos sadios" (FELDMAN e NELSON, 2004b), não requerem terapia intensiva e podem ser tratados, geralmente, sem internação.

Também existe grande variação nos distúrbios ácido-base da CAD. Embora a CAD seja, teoricamente, uma acidose normoclorêmica típica, decorrente do acúmulo de corpos cetônicos no sangue, observou-se que esse distúrbio pode variar de acidose normoclorêmica até acidose hiperclorêmica pura (ADROGUÉ et al., 1982; PAULSON e GADALLAH, 1993). Quadros mistos de acidose hiperclorêmica e normoclorêmica podem ocorrer em uma grande parcela dos pacientes (43\% em um relato [ADROGUÉ et al., 1982]). Pacientes humanos capazes de manter o aporte de água e sal durante o desenvolvimento da CAD, têm função renal mais preservada, em decorrência da manutenção do volume sangüíneo. Esses pacientes sofrem de graus variados de acidose hiperclorêmica em conseqüência da excreção urinária preferencial de cátions junto de ânions cetônicos (KITABCHI et al., 2001). Acredita-se que o mesmo ocorra em cães (BRUYETTE, 1997), embora essa teoria não tenha sido confirmada em estudos clínicos.

Pacientes com maior grau de desidratação geralmente sofrem de acidose mais grave e, predominantemente, normoclorêmica, em decorrência do maior acúmulo de corpos cetônicos e outros metabólitos (e.g., toxinas urêmicas, lactato) (ADROGUÉ; EKNOYAN; SUKI, 1984; PAULSON e GADALLAH, 1993). Pacientes com outras complicações, como êmese grave e persistente, podem apresentar pH sangüíneo normal ou até mesmo alcalemia (ADROGUÉ; EKNOYAN; SUKI, 1984; OKUDA et al., 1996). 
Portanto, na CAD, a concentração de cloro plasmático tem um papel importante nas alterações do equilíbrio ácido-base. Por muito tempo o cloro foi considerado um "parceiro passivo" do sódio, que é ativamente transportado através dos túbulos renais, pois as alterações no balaço hídrico corpóreo geralmente afetam, proporcionalmente, as concentrações de sódio e cloro (DE MORAIS, 1999).

Cães com CAD invariavelmente têm diminuição dos estoques corpóreos de sódio, a despeito da concentração sérica mensurada. Em uma casuística, 62\% dos cães com CAD apresentaram hiponatremia e a hipernatremia ocorreu em $7 \%$ dos casos (FELDMAN e NELSON, 2004b). A hiponatremia é resultante da diurese osmótica, decorrente da glicosúria e cetonúria. Além disso, a concentração sérica de sódio é, geralmente, baixa na CAD em decorrência do fluxo de água do espaço intracelular para o extracelular, por causa do efeito osmótico da hiperglicemia. Para avaliar a gravidade da depleção, a concentração sérica de sódio pode ser corrigida, adicionando-se 1,6 mEq ao sódio mensurado, para cada $100 \mathrm{mg} / \mathrm{dL}$ de glicose acima de 100 mg/dL (KITABCHI et al., 2001). Cães com CAD geralmente não apresentam quadro de hiperosmolalidade grave. Por esse motivo a correção do sódio em relação à hiperglicemia não é rotineiramente usada na clínica veterinária de cães (DUARTE et al., 2002).

A depleção de potássio também é comum em cães com CAD. As manifestações clínicas da hipocalemia resultam de alterações na condução elétrica das membranas celulares: fraqueza muscular, arritmias cardíacas, paralisia, letargia. Essas alterações geralmente não ocorrem até que a concentração sérica de potássio seja $<2,5 \mathrm{mEq} / \mathrm{L}$. A depleção de potássio ocorre devido à diurese osmótica, diminuição da ingestão e perdas por vômito ou diarréia (FELDMAN e NELSON, 2004b). Os valores séricos de potássio, entretanto, podem se apresentar normais ou até elevados, em decorrência da insulinopenia e outros fatores como 
hiperosmolalidade, redução da excreção renal do potássio e liberação de potássio das células, que acompanha o catabolismo protéico (ADROGUE et al., 1986; KITABCHI et al., 2001).

A depleção de fósforo na CAD é comum e também resulta da perda pela diurese osmótica e êmese, bem como pela diminuição do aporte nutricional decorrente da anorexia. As manifestações da hipofosfatemia aguda são raras e associadas à hipofosfatemia grave $(<1,5 \mathrm{mg} / \mathrm{dL})$ : anemia hemolítica, fraqueza muscular e alterações neurológicas,como convulsão ou coma (WILLARD et al., 1987). Outra complicação potencial da hipofosfatemia é a redução da concentração do 2,3-difosfoglicerato (2-3-DPG) nas hemácias. A deficiência do 2-3-DPG aumenta a afinidade da hemoglobina pelo oxigênio, resultando em hipóxia. Geralmente a hipofosfatemia ocorre após o início do tratamento da CAD (FISHER; KITABCHI, 1983). Na admissão, geralmente os pacientes estão hiperfosfatêmicos. Em um estudo, 94,7\% dos pacientes humanos com CAD apresentavam hiperfosfatemia antes do início do tratamento (KEBLER, MCDONALD; CADNAPAPHORNCHAI, 1985).

Mais recentemente, a hipocalcemia e a hipomagnesemia têm merecido atenção na clínica veterinária. Esses distúrbios foram descritos em pacientes críticos, incluindo a CAD (TOLL et al., 2002). Alguns autores postulam que a depleção de magnésio em pacientes com CAD poderia levar ao desenvolvimento de hipocalemia refratária ao tratamento, embora a hipomagnesemia não seja um distúrbio comum em cães diabéticos, quando comparada a felinos com DM (FINCHAM et al., 2004; NORRIS; NELSON; CHRISTOPHER, 1999). Acredita-se, também, que a hipocalcemia possa causar resistência insulínica e arritmias (HESS et al., 2000).

Cães com cetoacidose diabética freqüentemente apresentam condições como vômito e diarréia, que podem causar distúrbios ácido-base mistos (DE MORAIS; DIBARTOLA, 1999). Além disso, cães diabéticos freqüentemente têm doenças concorrentes, como o hiperadrenocorticismo, pancreatite aguda e neoplasias, que também podem causar 
desequilíbrios ácido-base (HESS et al., 2000). A identificação desses distúrbios é importante para o tratamento adequado e a detecção precoce de complicações (DE MORAIS; DIBARTOLA, 1999).

A CAD envolve uma série de anormalidades do metabolismo intermediário, do volume e da composição dos líquidos corpóreos, cujas características não foram completamente avaliadas. A correção apropriada das alterações do equilíbrio ácido-base e hidreletrolítico é crítica para a sobrevivência do paciente e, para tanto, é essencial a compreensão desses distúrbios. Familiarizando-se com as conseqüências fisiológicas da CAD, o clínico poderá desenvolver uma abordagem racional e tratamento efetivo do paciente. 


\section{JUSTIFICATIVA}

Embora CAD seja um distúrbio comum e de alta mortalidade, os padrões dos distúrbios ácido-base de cães com CAD ainda não foram avaliados objetivamente. Muitas das assunções sobre a CAD em cães são generalizadas com base em dados de pacientes humanos e estudos experimentais em cães.

\section{OBJETIVOS}

- Descrever os distúrbios ácido-base e eletrolíticos de cães com cetoacidose e cetose diabética e caracterizá-los segundo a freqüência de ocorrência, adequação dos mecanismos de compensação e ocorrência de distúrbios mistos. 


\section{Materiais e Métodos ${ }^{1}$}

\subsection{Animais}

Cães diabéticos (grupo de estudo): foram selecionados 40 cães com diabetes mellitus (DM) apresentado cetonúria. O diagnóstico de DM foi baseado na deteç̧ão de hiperglicemia ( $>250 \mathrm{mg} / \mathrm{dL}$ ) e glicosúria concomitantes. Cada paciente foi incluído no grupo estudo apenas uma vez (a primeira admissão). Os animais foram posteriormente distribuídos em dois subgrupos, segundo critérios clínicos (FELDMAN e NELSON, 2004b):

- cães com cetoacidose diabética $(\mathbf{C A D}, \mathbf{n}=\mathbf{2 2})$ : cães diabéticos com cetonúria e sintomas compatíveis com doença metabólica grave (êmese, anorexia ou disorexia, letargia), como também cães que receberam tratamento com insulina regular e fluidoterapia durante o atendimento no HOVET-FMVZ-USP e foram encaminhados para internação;

- cães com cetose diabética $(\mathbf{C D}, \mathbf{n}=\mathbf{1 8})$ : cães sem de sintomas de doença metabólica grave, exceto aqueles atribuídos ao diabetes não tratado ou mal controlado (eg, poliúria, polidipsia, emagrecimento; polifagia, catarata). Apenas foram incluídos nesse grupo cães que receberam tratamento ambulatorial e foram dispensados, no mesmo dia, para tratamento domiciliar.

A revisão dos prontuários e a classificação dos pacientes foram realizadas por dois veterinários e, as divergências, arbitradas por consenso.

O estudo foi realizado nos Serviços de Clínica Médica e de Pronto Atendimento Médico de Pequenos Animais do Departamento de Clínica Médica/Hospital Veterinário da Faculdade de Medicina Veterinária e Zootecnia da USP (HOVET-FMVZ-USP), no período entre março de 2003 e agosto de 2005.

${ }^{1}$ O delineamento experimental do presente estudo foi aprovado Comissões de Bioética da FMVZ-USP e Ética do HOVET-FMVZ/USP. 
Cães sadios (grupo controle): para comparações com o grupo de estudo, foram avaliados 37 cães, de idades variadas e clinicamente hígidos, que tinham glicemia $\geq 65 \mathrm{mg} / \mathrm{dL}$ e $<125 \mathrm{mg} / \mathrm{dL}$ e ausência de glicose e corpos cetônicos na urina. As colheitas foram realizadas no período da manhã (antes do meio dia) e os animais estavam em jejum alimentar desde a noite anterior à colheita de sangue e urina.

\subsection{Métodos}

As amostras de sangue para avaliação do $\mathrm{pH}$, gases sangüíneos e eletrólitos foram colhidas da artéria femoral utilizando-se seringa plástica contendo heparina liofilizada ${ }^{2}$. A amostra foi manipulada anaerobicamente e processada em menos de 15 minutos após a colheita. Para realização das determinações bioquímicas do soro (glicose, magnésio e $\beta$-hidroxibutirato), uma amostra de sangue venoso foi colhida, transferida para tubo contendo gel separador do soro $^{3}$ e centrifugada a $1500 \mathrm{~g}$ durante 15 minutos. A amostra de soro obtida foi dividida em 2 ou 3 alíquotas e, a critério clínico, uma alíquota foi processada imediatamente, para realização das determinações bioquímicas necessárias para a avaliação inicial do animal. As demais foram congeladas $\left(-70^{\circ} \mathrm{C}\right)$ e reservadas para posterior processamento. Uma amostra de urina foi colhida para determinação semi-quantitativa da glicose e corpos cetônicos (acetona e acetoacetato) por meio de tiras reagentes ${ }^{4}$. As amostras de sangue e urina foram colhidas previamente à instituição de tratamento com fluidos e insulina regular.

Todos os exames foram realizados no Laboratório Clínico do Departamento de Clínica Médica/HOVET-FMVZ-USP.

\footnotetext{
${ }^{2}$ Seringa para Gasometria BD Preset, Becton, Dickinson and Co., Plymouth.

3 Tubo Vacutainer SST, Becton, Dickinson and Co., Plymouth.

${ }^{4}$ Gluketur test, Roche Diagnostics, Mannhein.
} 
Determinação da glicemia: para triagem dos cães diabéticos a glicemia foi determinada com o auxílio de sensores portáteis. A glicose sérica foi posteriormente mensurada pelo método da glicose-oxidase ${ }^{5}$ em analisador bioquímico automático ${ }^{6}$.

Determinação da uréia sérica: a uréia sérica foi determinada pelo método da urease/glutamato deidrogenase $(\mathrm{GLDH})^{7}$ em analisador bioquímico automático ${ }^{6}$.

Determinação do $\beta$-hidroxibutirato: a concentração do $\beta$-hidroxibutirato sérico foi determinada pelo método da oxidação pela $\beta$-HBO-desidrogenase ${ }^{8}$ em analisador bioquímico automático ${ }^{6}$.

Determinação do pH sangüíneo e hemogasometria: foram mensurados o $\mathrm{pH}$ e as pressões parciais de $\mathrm{CO}_{2}\left(\mathrm{PCO}_{2}\right)$ e de $\mathrm{O}_{2}\left(\mathrm{PO}_{2}\right)$ do sangue arterial em analisador automático? . A concentração plasmática de bicarbonato $\left(\left[\mathrm{HCO}_{3}{ }^{-}\right]\right)$e o déficit/excesso de base (BE) foram calculados automaticamente e corrigidos para a temperatura retal do animal, por meio de nomogramas do aparelho.

Determinação dos eletrólitos: as determinações de sódio $\left(\mathrm{Na}^{+}\right)$, potássio $\left(\mathrm{K}^{+}\right)$, cloro $\left(\mathrm{Cl}^{-}\right)$e cálcio ionizado $\left(\mathrm{Ca}^{2+}\right)$ plasmáticos foram realizadas pelo método de eletrodos íons seletivos $^{8}$. O magnésio total sérico $(\mathrm{Mg})$ foi mensurado pelo método da calmagita ${ }^{10} \mathrm{em}$ analisador bioquímico automático ${ }^{6}$.

Determinação do fósforo inorgânico sérico: a determinação do fósforo inorgânico sérico foi realizada pelo método do molibdato em meio ácido ${ }^{11}$ em analisador bioquímico automático ${ }^{6}$.

\footnotetext{
${ }^{5}$ Glicose, Biosystems AS, Barcelona.

${ }^{6}$ Liasys, AMS, Roma.

${ }^{7}$ Urea FS, Diasys Diagnostic Systems, Holzhein.

${ }^{8}$ Autokit 3-HB, Wako Chemicals USA, Inc. Richmond.

${ }^{9}$ OMNI 4, AVL Medical Instruments, Graz.

${ }^{10}$ Magnésio, Labtest Diagnóstica, Lagoa Santa.

${ }^{11}$ Fósforo, Biosystems AS, Barcelona.
} 


\subsection{Avaliação do equilíbrio ácido-báse}

Todos aos animais selecionados foram avaliados individualmente e de modo sistemático pelo método de Van Slyke/Henderson-Hasselbalch (Quadro 1).

1. Identificar se existe um distúrbio ácido-base:

A. $\mathrm{pH}$ abaixo do limite inferior dos valores de referência: acidemia (ver 2.A)

B. $\mathrm{pH}$ acima do limite superior dos valores de referência: alcalemia (ver 2.B)

C. $\mathrm{pH}$ dentro dos valores de referência: ver 2

2. Identificar o distúrbio predominante:

A. $\checkmark\left[\mathrm{HCO}_{3}\right]$ abaixo dos valores de referência: acidose metabólica $\checkmark \mathrm{PCO}_{2}$ acima dos valores de referência: acidose respiratória

B. $\checkmark\left[\mathrm{HCO}_{3}^{-}\right]$acima dos valores de referência: alcalose metabólica $\checkmark \mathrm{PCO}_{2}$ abaixo dos valores de referência: alcalose respiratória

3. Checar o valor do BE

$\checkmark \downarrow \mathrm{BE}$ acidose metabólica

$\checkmark \uparrow$ BE alcalose metabólica

$\checkmark$ BE normal: distúrbio respiratório

4. Avaliar se a resposta compensatória é adequada*:

A. Acidose metabólica (para cada $1 \mathrm{mmol} / \mathrm{L}$ que diminuir a $\left[\mathrm{HCO}_{3}{ }^{-}\right]$): $\checkmark$ redução de $0,7( \pm 2) \mathrm{mm} \mathrm{Hg}$ na $\mathrm{PCO}_{2}$

B. Acidose respiratória (para cada $1 \mathrm{~mm} \mathrm{Hg}$ de aumento na $\mathrm{PCO}_{2}$ ): $\checkmark$ aumento de $0,15 \mathrm{mmol} / \mathrm{L}$ na $\left[\mathrm{HCO}_{3}^{-}\right]$(acidose respiratória aguda)

$\checkmark$ aumento de 0,034 a $0,039 \mathrm{mmol} / \mathrm{L}$ na $\left[\mathrm{HCO}_{3}\right]$ (acidose respiratória crônica)

C. Alcalose metabólica (para cada $1 \mathrm{mmol} / \mathrm{L}$ de aumento na $\left[\mathrm{HCO}_{3}{ }^{-}\right]$):

$\checkmark$ aumento de $0,7( \pm 2) \mathrm{mm} \mathrm{Hg}$ na $\mathrm{PCO}_{2}$

D. Alcalose respiratória (para cada $1 \mathrm{~mm} \mathrm{Hg}$ de diminuição na $\mathrm{PCO}_{2}$ ):

$\checkmark$ aguda $\left(<24 \mathrm{~h}\right.$ ): diminuição de $0,2 \mathrm{mmol} / \mathrm{L}$ na $\left[\mathrm{HCO}_{3}{ }^{-}\right]$

$\checkmark$ crônica (>48 h): diminuição de $0,55 \mathrm{mmol} / \mathrm{L}$ na $\left[\mathrm{HCO}_{3}{ }^{-}\right]$

OBS: compensação adequada: distúrbio ácido-base simples compensação inadequada: distúrbio ácido-base misto

5. calcular o anion gap (AG):

$$
\mathrm{AG}=\left(\left[\mathrm{Na}^{+}\right]+\left[\mathrm{K}^{+}\right]\right)-\left(\left[\mathrm{HCO}_{3}{ }^{-}\right]+\left[\mathrm{Cl}^{-}\right]\right)
$$

$\checkmark$ AG aumentado: acidose metabólica do tipo normoclorêmica.

$\checkmark$ AG normal: acidose metabólica do tipo hiperclorêmica

$\left[\mathrm{HCO}_{3}\right]$ : concentração plasmática do bicarbonato; $\mathrm{PCO}_{2}$ : pressão parcial de dióxido de carbono; BE: déficit de base; AG: anion gap; $\mathrm{Na}^{+}$: concentração plasmática do sódio; $\mathrm{Cl}^{-}$: concentração plasmática do cloro.

* Para calcular a resposta compensatória foram usados os valores médios da $\mathrm{PCO}_{2}$ e $\left[\mathrm{HCO}_{3}\right]$ dos cães do grupo controle $(33,4 \mathrm{~mm} \mathrm{Hg}$ e 21,0 $\mathrm{mmol} / \mathrm{L}$, respectivamente).

Fonte: DiBARTOLA, S.P. Introduction to acid-base disorders acidosis. In Fluid Therapy in Small Animal Practice. 2 ed. Philadelphia, W.B. Saunders, 1999, p.189-210.

Quadro 1 - Algoritmo para avaliação dos distúrbios ácido-base e interpretação de possíveis alterações. 


\subsection{Análise estatística}

Muitas variáveis tiveram distribuição não Gaussiana ou não houve homogeneidade de sua variância entre os grupos (Apêndice). Portanto, as diferenças entre as variáveis contínuas dos grupos e subgrupos foram comparadas pelo teste não paramétrico de Mann-Whitney, exceto idade e peso, que foram avaliadas pelo teste paramétrico F de ANOVA. Para análise das diferenças entre proporções de variáveis categóricas foi empregado o teste de Quiquadrado $\left(\chi^{2}\right)$ ou o teste exato de Fisher. A diferença entre os subgrupos quanto à freqüência de distúrbios ácido-base e eletrolíticos foi avaliada pelo teste do $\chi^{2}$. Os valores de referência para esse estudo foram estimados pelo intervalo compreendido entre dois desvios-padrão da média das determinações dos cães do grupo controle, com exceção das variáveis de distribuição não Gaussiana, cujos valores de referência foram calculados pelo intervalo compreendido entre o percentis $2,5 \%$ e $97,5 \%$. A análise foi realizada com o auxílio de programa computadorizado. ${ }^{12}$ A menos que declarado o contrário, as variáveis foram expressas em mediana e respectivo intervalo de variação (valores mínimo e máximo). Para todas as análises estatísticas, um valor de $P<0,05$ foi considerado significante.

\footnotetext{
${ }^{12}$ SPSS for Windows 8.0, SPSS Inc., Chicago.
} 


\section{Resultados}

Os cães diabéticos apresentaram idade média de 10 anos (desvio-padrão: 3,2 anos; variação de 5 a 18 anos). Não houve diferença estatística entre a faixa etária dos cães dos subgrupos de estudo. Também não houve diferença em relação à distribuição segundo seu peso (média: 13,6 \pm 9,3 kg; variação: 4,2 a 37,4 kg). Quanto à distribuição sexual, houve predominância de fêmeas em ambos os subgrupos de estudo. Dos casos avaliados, 31 eram fêmeas, sendo que apenas 10 delas eram castradas. Os machos corresponderam a nove animais (nenhum castrado). Não houve diferença na distribuição, segundo o sexo, entre os subgrupos. As características dos animais na ocasião do atendimento inicial no hospital estão sumarizadas na tabela 1 .

Tabela 1 - Características dos cães diabéticos dos subgrupos cetoacidose diabética (CAD) e cetose diabética (CD) - São Paulo - mar 2003 - ago 2005

\begin{tabular}{|c|c|c|c|c|}
\hline & $\begin{array}{c}\text { CAD } \\
(n=22)\end{array}$ & $\begin{array}{c}\text { CD } \\
(n=18)\end{array}$ & $\begin{array}{c}\text { Valores } \\
\text { de } P\end{array}$ & $\begin{array}{l}\text { Valores de } \\
\text { referência }\end{array}$ \\
\hline Sexo & & & & - \\
\hline Fêmeas/machos (n) & $17 / 5$ & $14 / 4$ & 0,640 & - \\
\hline Fêmeas castradas (n) & 5 & 5 & 0,490 & - \\
\hline Recém diagnosticados & 12 & 10 & 0,801 & \\
\hline Idade (anos) $^{*}$ & $10 \pm 3,8$ & $9,9 \pm 2,4$ & 0,892 & - \\
\hline Peso $(\mathrm{kg})^{*}$ & $14,9 \pm 10,0$ & $12,0 \pm 8,4$ & 0,328 & - \\
\hline Glicose sérica (mg/dL) & $450(273$ a 1670$)$ & 492 (341 a 750$)$ & 0,619 & 65 a 125 \\
\hline$(\mathrm{mmol} / \mathrm{L})$ & $25(15$ a 93$)$ & $27(19$ a 42$)$ & & 3,6 a 6,9 \\
\hline$\beta-\mathrm{HOB}^{(1)}(\mathrm{mmol} / \mathrm{L})$ & $7,0(3,1$ a 10,5$)$ & $3,2(0,1$ a 7,7$)$ & $<0,001$ & 0,02 a 0,15 \\
\hline Uréia sérica (mg/dL) & 64,5 (17 a 343) & $40,9(15$ a 71$)$ & 0,079 & \\
\hline
\end{tabular}

(1) $\beta$-HOB: $\beta$-hidroxibutirato sérico

*Média \pm DP

Segundo a definição racial, os animais foram distribuídos em: Poodle $(n=12$; incluindo as variedades Poodle Miniatura, Toy e possíveis cruzamentos entre elas); Rottweiler (3); Terrier Brasileiro (3); Beagle (2); Husky Siberiano (1); Dálmata (1); Dobermann Pinscher (1); Pastor Alemão (1) e 16 cães sem raça definida. 
As queixas principais dos proprietários dos cães diabéticos do subgrupo CAD foram êmese $(n=8)$, anorexia (6), diminuição do apetite (5) e letargia (3). No subgrupo CD, as queixas principais foram: poliúria e polidipsia $(n=4)$, poliúria, polidipsia, perda de peso e polifagia (3), perda de peso (3), catarata (3), paralisia de face (1) e neoplasia mamária (1). Dois cães foram encaminhados por causa de mau controle do diabetes e um cão foi encaminhado por outro Serviço do Hospital, em decorrência da detecção de cetonúria. As freqüências dos principais achados do histórico e exame físico dos cães do grupo de estudo estão arroladas na tabela 2.

Tabela 2 - Manifestações clínicas dos cães diabéticos do grupo de estudo e seus subgrupos cetoacidose diabética (CAD) e cetose diabética (CD) - São Paulo - mar 2003 - ago 2005

\begin{tabular}{lccc}
\hline & Todos $(\mathbf{n}=\mathbf{4 0})$ & CAD $(\mathbf{n}=\mathbf{2 2})$ & CD $(\mathbf{n}=\mathbf{1 8})$ \\
\hline Achados clínicos & $\mathbf{n}(\mathbf{\%})$ & $\mathbf{n}(\mathbf{\%})$ & $\mathbf{n ~ ( \% )}$ \\
\hline Poliúria/polidipsia & $32(80)$ & $16(73)$ & $16(89)$ \\
Desidratação & $19(48)$ & $13(59)$ & $6(33)$ \\
Anorexia/disorexia & $18(45)$ & $18(82)$ & 0 \\
Êmese & $17(43)$ & $17(77)$ & 0 \\
Emagrecimento & $16(40)$ & $8(36)$ & $8(44)$ \\
Hálito cetônico & $14(35)$ & $11(50)$ & $3(17)$ \\
Letargia & $11(28)$ & $8(36)$ & $3(17)$ \\
Polifagia & $8(20)$ & $1(5)$ & $7(39)$ \\
Hipotermia $\left(<37,7^{\circ} \mathrm{C}\right)$ & $7(18)$ & $5(23)$ & $2(11)$ \\
Catarata & $6(15)$ & $1(5)$ & $5(28)$ \\
Dispnéia & $6(15)$ & $3(14)$ & $3(17)$ \\
Ataxia & $5(13)$ & $4(18)$ & $1(6)$ \\
Caquexia & $5(13)$ & $4(18)$ & $1(6)$ \\
Abdômen pendular & $5(13)$ & $3(14)$ & $2(11)$ \\
Sopro & $4(10)$ & $4(18)$ & 0 \\
Hipertermia $\left(<39,3^{\circ} \mathrm{C}\right)$ & $3(8)$ & 0 & $3(17)$ \\
Dor abdominal & $2(5)$ & $1(5)$ & $1(6)$ \\
\hline
\end{tabular}

O tempo decorrido entre a observação dos sintomas e o atendimento do animal variou de 4 a 120 dias no subgrupo CD (mediana: 12 dias) e de 1 a 30 dias (mediana: 4 dias) no subgrupo $\mathrm{CAD}$ e foi diferente $(P=0,004)$ entre eles. Informações sobre o tempo do início dos sintomas não foram mencionados em quatro prontuários (dois de cada subgrupo). 
Fatores que possam ter contribuído para o desenvolvimento da CAD nos cães em insulinoterapia $(\mathrm{n}=18)$ foram: hiperadrenocorticismo (HAC) endógeno (4), neoplasia mamária (4), infecção do trato urinário, (2) omissão da insulinoterapia (2), pancreatite (1), efusão pleural não esclarecida (1) e diestro (1). Os motivos para descompensação do diabetes não foram identificados em três animais. Os cães recém diagnosticados diabéticos $(\mathrm{n}=22)$ também apresentavam doenças associadas, entre elas, neoplasia mamária $(n=6)$, suspeita de HAC endógeno (6), pancreatite (1) e insuficiência renal (1).

Não houve diferença entre as concentrações séricas de glicose e uréia entre os subgrupos, porém a azotemia foi mais comum em pacientes com CAD $(n=14)$ do que em pacientes com $\mathrm{CD}(\mathrm{n}=4 ; P=0,012)$. A distribuição dos valores da uréia sérica do grupo controle foi diferente em relação ao subgrupo $\operatorname{CAD}(P=0,008)$, mas não em relação ao subgrupo $\mathrm{CD}(P=0,674)$.

Vinte e seis cães tiveram remissão da cetonúria e sobreviveram após o atendimento inicial e 18 deles são do grupo $\mathrm{CD}$. Nove cães morreram e dois foram submetidos à eutanásia no curso do tratamento, todos do grupo CAD. Três cães não retornaram ao hospital após o primeiro atendimento. 


\subsection{Distúrbios ácido-base}

As variáveis de avaliação do estado ácido-base foram diferentes entre os subgrupos de estudo (Tabela 3). Também foram diferentes entre os subgrupos de estudo e o grupo controle, com exceção do $\mathrm{pH}$ dos cães do subgrupo $\mathrm{CD}$ que não foi diferente do $\mathrm{pH}$ dos animais do grupo controle $(P=0,197)$.

Tabela 3 - Valores da mediana, mínimo e máximo de $\mathrm{pH}$ sangüíneo, pressão dos gases sangüíneos, déficit de base e anion gap dos cães dos subgrupos cetoacidose diabética (CAD) e cetose diabética (CD), São Paulo - mar 2003 - ago 2005

\begin{tabular}{|c|c|c|c|c|}
\hline & $\begin{array}{c}\text { CAD } \\
(n=22)\end{array}$ & $\begin{array}{c}\text { CD } \\
(n=18)\end{array}$ & $\begin{array}{c}\text { Valores } \\
\text { de } P\end{array}$ & $\begin{array}{l}\text { Valores de } \\
\text { referência }\end{array}$ \\
\hline pH sangüíneo & $7,262(7,001$ a 7,487$)$ & $7,407(7,267$ a 7,459$)$ & $<0,001$ & 7,37 a 7,47 \\
\hline $\mathrm{PCO}_{2}(\mathrm{~mm} \mathrm{Hg})^{(1)}$ & $22,0(13,9$ a 29,5$)$ & $28,7(14,2$ a 38,2$)$ & 0,001 & 26 a 41 \\
\hline $\mathrm{PO}_{2}(\mathrm{~mm} \mathrm{Hg})^{(2)}$ & $106,2(72,1$ a 299,9$)$ & $86,4(69,6$ a 147,0$)$ & 0,001 & 79 a 112 \\
\hline$\left[\mathrm{HCO}_{3}{ }^{-}\right](\mathrm{mmol} / \mathrm{L})^{(3)}$ & $9,0(5,3$ a 17,3$)$ & $17,3(6,2$ a 22,3$)$ & $<0,001$ & 17 a 25 \\
\hline $\mathrm{BE}(\mathrm{mmol} / \mathrm{L})^{(4)}$ & $-16,2(-24,4$ a $-3,1)$ & $-5,8(-17,2$ a 0,4$)$ & $<0,001$ & -6 a 2 \\
\hline $\mathrm{SO}_{2}(\%)^{(5)}$ & $95,8(88,2$ a 99,9$)$ & $95,9(91,7$ a 98,4$)$ & 0,861 & 94 a 99 \\
\hline $\mathrm{AG}(\mathrm{mmol} / \mathrm{L})^{(6)}$ & $32,2(14,0$ a 43,8$)$ & $22,9(10,6$ a 31,8$)$ & 0,008 & 11 a 23 \\
\hline
\end{tabular}

(1) Pressão parcial de dióxido de carbono. (2) Pressão parcial de oxigênio. (3) Bicarbonato plasmático. (4) Déficit de base. (5) Saturação sangüínea de oxigênio. (6) Anion gap.

A acidose foi o distúrbio ácido-base mais comum identificado (Gráfico 2). Dos 40 cães com DM, 27 apresentavam acidose (mediana da $\left[\mathrm{HCO}_{3}{ }^{-}\right]:$9,2 mmol/L; variação: 5,3 a 16,1 mmol/L). Vinte e um cães com acidose eram do subgrupo CAD. Acidemia concomitante foi identificada em 22 dos animais com acidose (mediana do pH: 7,269, variação: 7,001 a 7,446), sendo que, desses, 19 pertenciam ao subgrupo de cães com CAD. Acidemia grave $(<7,10)$ foi observada em quatro cães do grupo CAD. Todos os cães com acidose apresentavam diminuição do BE (mediana: -14,8; variação: -24,4 a -6,2 mmol/L), sugestivo de acidose metabólica.

A alcalose respiratória foi comum no grupo de estudo $(n=22 ; 55 \%)$. A hipocapnia foi observada em 18 cães do subgrupo CAD e quatro cães com CD. Seis pacientes apresentavam 
hipoxemia $\left(\mathrm{PO}_{2}:\right.$ 69,6 a 78,5mm Hg). As doenças concorrentes desses cães eram neoplasia mamária $(\mathrm{n}=2)$ e suspeita de $\mathrm{HAC}(\mathrm{n}=3)$. Quatro cães apresentaram aumento da $\mathrm{PO}_{2}(141,6$ a 299,9 mm Hg) em decorrência de suplementação de oxigênio por máscara, no momento da colheita da amostra de sangue. Distúrbios respiratórios simples não foram identificados na presente casuística.
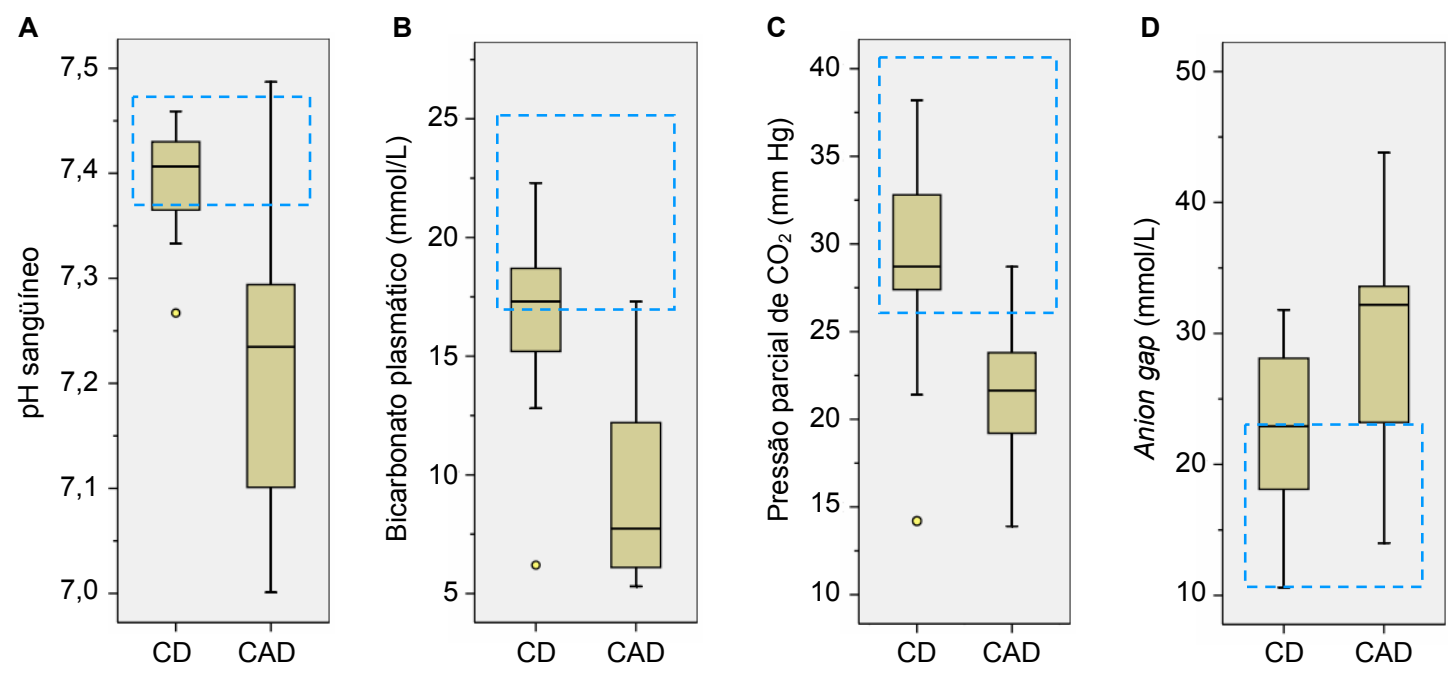

Gráfico 2 - Intervalo interquartílico (caixas), mediana (traços horizontais) e variação (traços verticais) dos valores de (A) $\mathrm{pH}$ sangüíneo; $(B)$ bicarbonato plasmático; $(C)$ pressão parcial de dióxido de carbono e (D) anion gap dos cães dos subgrupos cetose diabética (CD) e cetoacidose diabética (CAD). Os quadrados tracejados representam os intervalos de referência e, os círculos, os valores extremos, São Paulo - mar 2003 - ago 2005

O aumento do anion gap foi identificado em 20 dos cães com acidose o que é sugestivo de acidose normoclorêmica. Sete animais apresentavam anion gap $<23 \mathrm{mmol} / \mathrm{L}$, sugestivo de acidose hiperclorêmica. A maior parte dos cães com acidose normoclorêmica pertenciam ao subgrupo $\mathrm{CAD}(\mathrm{n}=16)$. A acidose normoclorêmica ocorreu em quatro cães do subgrupo $\mathrm{CD}$.

Dos 27 animais com acidose metabólica, 12 apresentavam compensação respiratória apropriada (dez deles pertenciam ao subgrupo CAD) e, os demais $(n=15)$, alcalose respiratória (Gráfico 3). Dos pacientes do subgrupo CD com acidose, a alcalose respiratória 
concomitante foi identificada em quatro. Dos cães com alcalose respiratória coexistente, todos apresentaram pH sangüíneo abaixo do limite inferior dos valores referência. Não houve diferença entre a freqüência dos distúrbios mistos entre os subgrupos de estudo $(P=0,66)$.

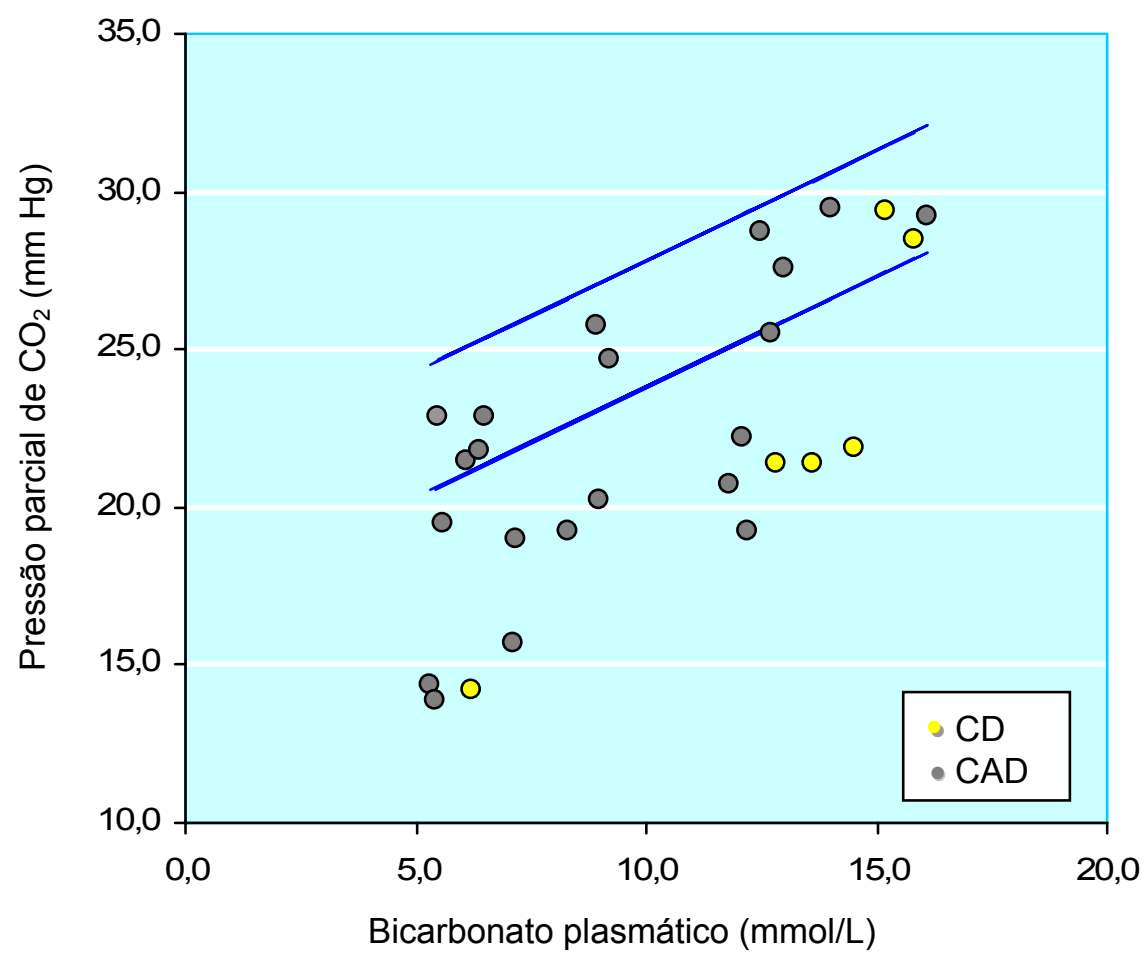

Gráfico 3 - Relação entre os valores da pressão parcial de $\mathrm{CO}_{2}\left(\mathrm{PCO}_{2}\right)$ e bicarbonato ([ $\left.\left.\mathrm{HCO}_{3}{ }^{-}\right]\right)$plasmáticos dos cães com acidose metabólica do grupo de estudo $(\mathrm{n}=27)$. As linhas diagonais azuis representam o intervalo da $\mathrm{PCO}_{2}$ considerado apropriado para a $\left[\mathrm{HCO}_{3}{ }^{-}\right]$, São Paulo - mar 2003 - ago 2005

Os distúrbios identificados nos cães com compensação inapropriada foram: suspeita de HAC ( $(=3)$, neoplasia mamária (2) gastrenterite hemorrágica (1), pancreatite (1), efusão pleural de origem desconhecida e infecção urinária (1). Cinco animais morreram durante o curso da doença. Naqueles cães com compensação considerada apropriada, as doenças concorrentes identificadas foram neoplasia mamária $(n=4)$, suspeita de HAC (3), insuficiência renal (1) e pancreatite (1). Quatro animais morreram e dois foram submetidos à eutanásia durante o atendimento. 


\subsection{Distúrbios eletrolíticos}

A distribuição dos valores de todos os eletrólitos foi diferente entre o grupo de estudo e o grupo controle, com exceção do magnésio. Não houve diferença na distribuição dos valores dos eletrólitos entre os subgrupos de estudo, com exceção do potássio plasmático (Tabela 3).

Tabela 4 - Valores da mediana, mínimo e máximo dos eletrólitos dos cães dos subgrupos cetoacidose diabética (CAD) e cetose diabética (CD), São Paulo - mar 2003 - ago 2005

\begin{tabular}{|c|c|c|c|c|}
\hline & $\begin{array}{c}\text { CAD } \\
(n=22)\end{array}$ & $\begin{array}{c}C D \\
(n=18) \\
\end{array}$ & $\begin{array}{c}\text { Valores } \\
\text { de } P \\
\end{array}$ & $\begin{array}{l}\text { Valores de } \\
\text { referência }\end{array}$ \\
\hline $\mathrm{Na}^{+}(\mathrm{mmol} / \mathrm{L})^{(1)}$ & $139,2(121,7$ a 158,6$)$ & $140,6(131,7$ a 154,3$)$ & 0,904 & 142 a 151 \\
\hline $\mathrm{Cl}^{-}(\mathrm{mmol} / \mathrm{L})^{(2)}$ & $104,1(82,7$ a 126,4$)$ & $104,7(90,7$ a 118,6$)$ & 0,968 & 105 a 115 \\
\hline $\mathrm{K}^{+}(\mathrm{mmol} / \mathrm{L})^{(3)}$ & $3,4(2,3$ a 5,0$)$ & $4,4(2,9$ a 5,8$)$ & $<0,001$ & 3,5 a 4,6 \\
\hline $\mathrm{Pi}(\mathrm{mg} / \mathrm{dL})^{(4)}$ & $6,3(3,3$ a 10,9$)$ & $6,4(4,0$ a 9,3$)$ & 0,946 & 2 a 7 \\
\hline $\mathrm{Ca}^{2+}(\mathrm{mmol} / \mathrm{L})^{(5)}$ & $1,121(0,741$ a 1,613$)$ & $1,163(0,827$ a 2,489$)$ & 0,778 & 1,22 a 1,48 \\
\hline $\operatorname{Mg}(\mathrm{mg} / \mathrm{dL})^{(6)}$ & $2,2(1,2$ a 3,7$)$ & $2,1(1,3$ a 2,6$)$ & 0,396 & 1,8 a 2,5 \\
\hline
\end{tabular}

(1) Sódio plasmático. (2) Cloro plasmático. (3) Potássio plasmático. (4) Fósforo inorgânico sérico. (5) Cálcio ionizado plasmático. (6) Magnésio total plasmático.

Hiponatremia e a hipocloremia foram os distúrbios eletrolíticos mais comuns, observados em $27(67 \%)$ e $21(52 \%)$ dos 40 cães com DM respectivamente (Gráfico 4). Hiponatremia e hipocloremia concomitantes ocorreram em 18 (45\%) cães do grupo de estudo. A hiponatremia ocorreu em 15 cães com CAD e 12 cães com CD. A hipocloremia foi observada em 13 cães do subgrupo CAD e em dez do subgrupo CD. A hipernatremia ocorreu em três pacientes (dois do subgrupo CAD). Quatro cães apresentaram hipercloremia (três do subgrupo CAD). A mediana do sódio do grupo de estudo foi igual a 139,5 mmol/L e, a do cloro, igual a 104,1 mmol/L.

A mediana do potássio plasmático $\left(\mathrm{K}^{+}\right)$do grupo de estudo foi igual a $3,8 \mathrm{mmol} / \mathrm{L}$. A hipocalemia ocorreu em 14 cães (35\%). No subgrupo CAD houve uma maior freqüência de hipocalemia $(n=13)$. A hipercalemia foi mais comum no subgrupo $\operatorname{CD}(n=8)$. No subgrupo 
CAD apenas dois pacientes apresentaram hipercalemia $\left(\mathrm{K}^{+}=4,78\right.$ e $\left.5,01 \mathrm{mmol} / \mathrm{L}\right)$. A ocorrência desses distúrbios foi diferente entre os subgrupos de estudo $(P=0,0005)$.
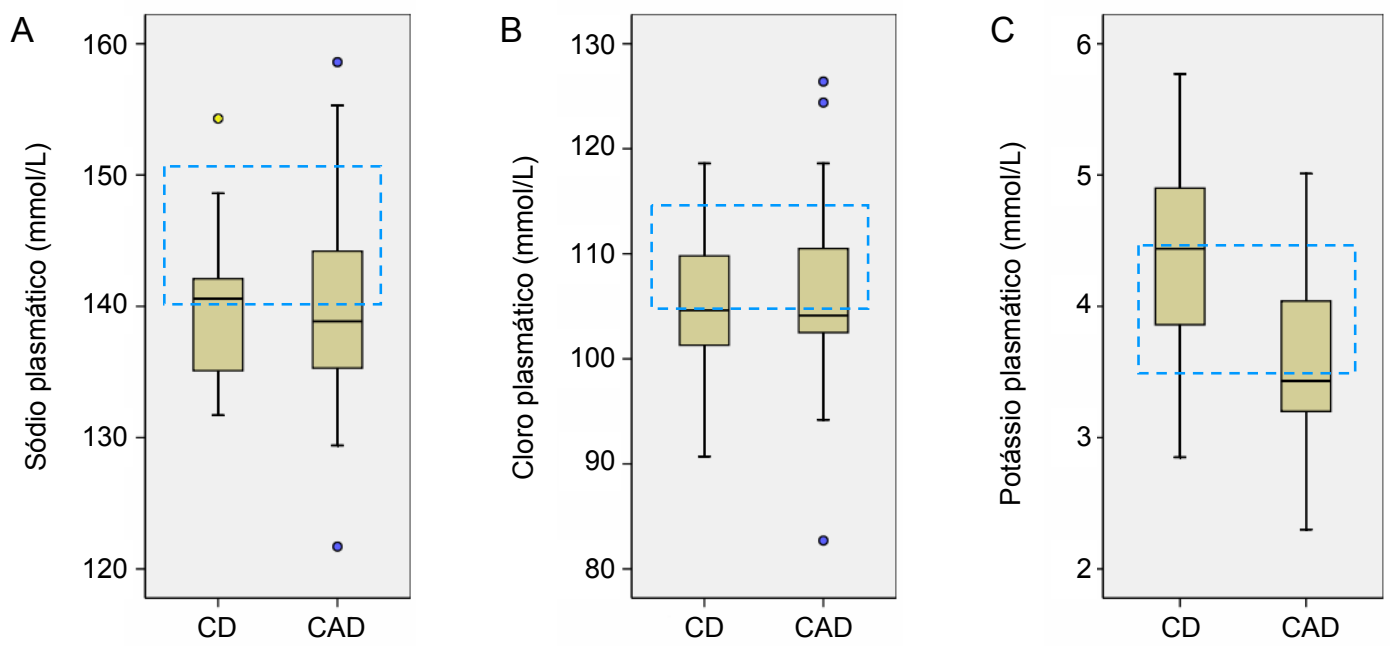

Gráfico 4 - Intervalo interquartílico (caixas), mediana (traços horizontais) e variação (traços verticais) dos valores de $(A)$ sódio plasmático; $(B)$ cloro plasmático e $(C)$ potássio plasmático dos cães dos subgrupos cetose diabética (CD) e cetoacidose diabética (CAD). Os quadrados tracejados representam os intervalos de referência e, os círculos, os valores extremos, São Paulo - mar 2003 - ago 2005

A mediana do fósforo sérico foi igual a $6,3 \mathrm{mg} / \mathrm{dL}$. A distribuição dos valores do fósforo inorgânico sérico foi semelhante entre os subgrupos de estudo. A hiperfosfatemia foi comum em ambos os subgrupos (oito pacientes do subgrupo CAD e sete do CD). Nenhum paciente apresentou hipofosfatemia (Gráfico 5).

A mediana do cálcio ionizado plasmático $\left(\mathrm{Ca}^{2+}\right)$ do grupo de estudo foi igual a 1,14 mmol/L. A maior parte dos pacientes $(\mathrm{n}=26 ; 65 \%)$ apresentou hipocalcemia por ocasião do atendimento inicial ( $n=15$ e $n=11$, subgrupo CAD e $C D$, respectivamente). Valores de $\mathrm{Ca}^{2+}$ acima do normal foram observados em apenas dois pacientes, um de cada subgrupo, $\left(\mathrm{Ca}^{2+}: 1,613\right.$ e 2,489 mmol/L, subgrupo CAD e CD, respectivamente). 

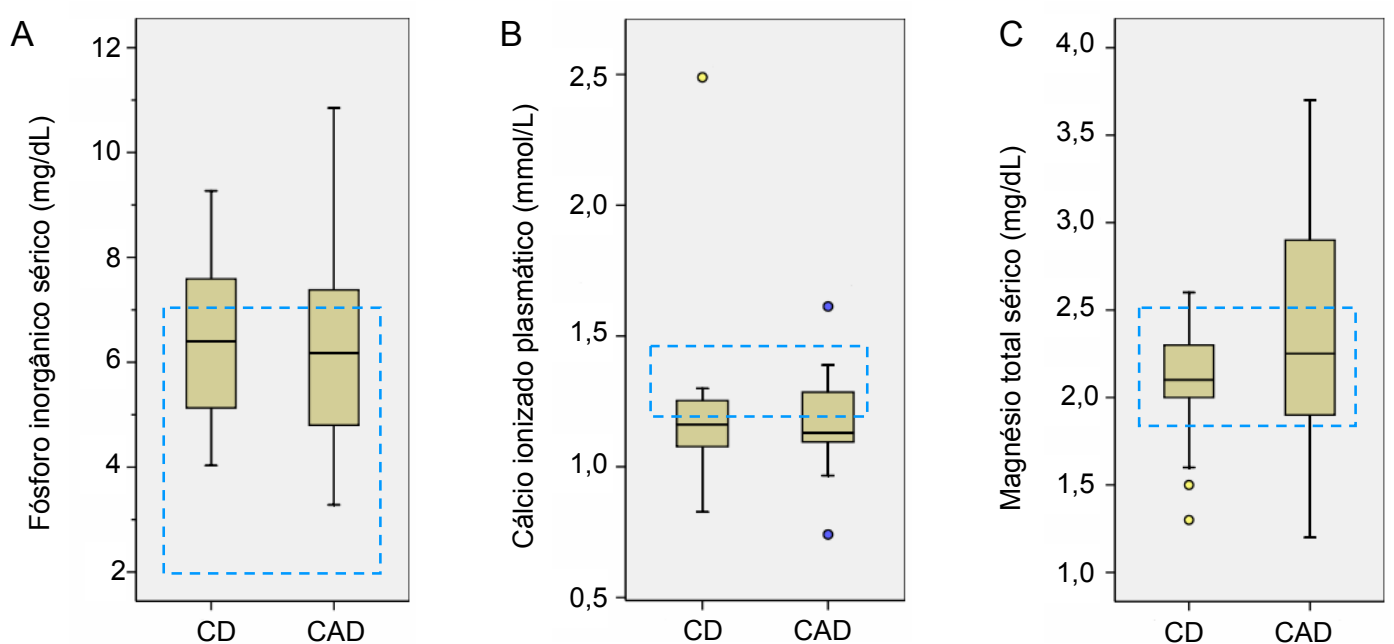

Gráfico 5 - Intervalo interquartílico (caixas) mediana, (traços horizontais) e variação (traços verticais) dos valores de $(A)$ fósforo inorgânico sérico; $(B)$ cálcio ionizado plasmático e $(C)$ magnésio total sérico dos cães dos subgrupos cetose diabética (CD) e cetoacidose diabética (CAD). Os quadrados tracejados representam os intervalos de referência e, os círculos, os valores extremos, São Paulo - mar 2003 ago 2005

A mediana da concentração de magnésio sérico total do grupo de estudo foi de 2,17 mg/dL. A hipermagnesemia foi observada em sete pacientes com CAD e apenas um com CD. A hipomagnesemia ocorreu em cinco cães do grupo CAD e quatro do subgrupo CD. Não houve diferença estatística $(P=0,098)$ na freqüência desses distúrbios. 


\section{DISCUSSÃO}

\subsection{Sobre os cães diabéticos}

O grupo de cães diabéticos foi constituído por animais em insulinoterapia e por cães recém diagnosticados como diabéticos, sem terapia prévia com insulina, que apresentavam cetonúria. Ao selecionar esses animais, o objetivo foi simular uma população com graus variados de descompensação hiperglicêmica, na qual testes para detecção de distúrbios ácidobase seriam pertinentes. Os cães foram incluídos apenas uma vez no estudo, pois a inclusão do mesmo animal com múltiplas admissões, o que não é raro, poderia causar tendenciosidade (“bias”) na análise dos dados.

A idade média dos cães diabéticos do grupo de estudo (aproximadamente 10 anos) é similar à descrita na literatura, na qual também se constata a maior ocorrência da doença em cães idosos (MARMOR et al., 1982; HESS et al., 2000; DUARTE, 2002; FELDMAN e NELSON, 2004a).

Quanto à distribuição sexual, observou-se uma predominância marcante de fêmeas no grupo de estudo (77\%). A relação fêmeas:machos da presente casuística é de aproximadamente $3,4: 1$, semelhante a estudos norte-americanos, nos quais também se observa uma maior ocorrência do DM em fêmeas, (MARMOR et al., 1982). Acredita-se, também, que cadelas diabéticas sejam mais predispostas a desenvolver $\mathrm{CAD}$, provavelmente em decorrência da resistência insulínica relacionada ao diestro (FELDMAN e NELSON, 2004b). Em um estudo de 21 cães com CAD, 17 (81\%) eram fêmeas (MACINTIRE, 1993).

Os achados clínicos observados nos cães diabéticos foram semelhantes aos previamente descritos (FELDMAN e NELSON, 2004a; HESS et al., 2000; MACINTIRE, 1993). Poliúria e polidipsia, desidratação, anorexia ou diminuição do apetite, êmese, emagrecimento, letargia e polifagia foram as principais manifestações do diabetes e a 
freqüência desses achados foi muito similar à casuística de Hess et al. (2000), em um estudo retrospectivo de 221 casos de DM em cães.

A mortalidade dos cães com CAD foi alta (50\%), o que era esperado pois, em estudos conduzidos em paises desenvolvidos, a mortalidade é de 30 a 40\% (FELDMAN e NELSON, 2004b; MACINTIRE, 1993). Muitos cães com CAD sofrem de doenças concomitantes graves e, além disso, o custo do tratamento e os cuidados posteriores com o cão diabético podem influir na decisão do proprietário a seguir com o tratamento.

\subsection{Sobre os distúrbios ácido-base}

Cães do subgrupo CAD apresentaram alterações laboratoriais compatíveis com acidose orgânica, incluindo acidemia e acidose metabólica, hipocapnia e aumento do anion gap. As alterações hemogasométricas dos cães do subgrupo CAD foram semelhantes às observadas em outro estudo (MACINTIRE, 1993). Os cães diabéticos do subgrupo CD apresentaram as medianas de $\mathrm{pH}$ sangüíneo, $\left[\mathrm{HCO}_{3}{ }^{-}\right]$, déficit de base e anion gap dentro dos valores de normalidade. Isso reforça a idéia de que, em geral, esses animais apresentaram equilíbrio ácido-básico preservado.

Dos cães com acidose metabólica, sete (26\%) tinham anion gap menor do que $23 \mathrm{mmol} / \mathrm{L}$, sugestivo de acidose hiperclorêmica. A maior parte desses cães $(\mathrm{n}=5)$ pertencia ao subgrupo CD. Esses cães também tinham função renal melhor preservada, pois a maior parte dos cães com CD (78\%) não apresentava azotemia, baseando-se nos valores de uréia sérica. A acidose hiperclorêmica é mais freqüente em seres humanos com aporte adequado de água e conseqüente manutenção da hidratação durante o desenvolvimento da CAD. Nesses pacientes ocorre uma excreção urinária preferencial de cátions junto de ânions cetônicos e o cloro é excretado em menor grau (DE MORAIS, 1999; KITABCHI et al., 2001). A acidose hiperclorêmica pura também foi observada em dois cães com CAD. 
A ocorrência de hipercloremia e aumento do anion gap concomitantes em pacientes com $\mathrm{CAD}$ é comum. Um índice freqüentemente empregado para detecção desse distúrbio misto é a relação entre o aumento do anion gap e a diminuição do $\left[\mathrm{HCO}_{3}{ }^{-}\right]$("relação $\Delta \mathrm{AG} / \Delta \mathrm{HCO}_{3}{ }^{-’}$ ) e a relação sódio/cloro (DIBARTOLA, 1999b). O emprego desses índices, entretanto, ainda é bastante controverso em medicina humana, quanto à sua validade e importância clínica (ADROGUÉ et al., 1984; PAULSON e GADALLAH, 1993; OKUDA et al., 1996). Por esse motivo, e também em decorrência do pequeno número de animais para comparações, optou-se não utilizá-los nesse estudo.

Foi observada uma grande ocorrência de alcalose respiratória associada à acidose metabólica (55\%). A alcalose respiratória é o mecanismo compensatório esperado nos quadros de acidose metabólica. Porém, na presente casuística, observou-se uma diminuição da $\mathrm{PCO}_{2}$ além dos limites considerados apropriados e, apesar dos distúrbios serem opostos, esses pacientes ainda apresentavam acidemia.

O motivo para esse achado não foi elucidado. As causas de alcalose respiratória primária incluem hipoxemia pela estimulação dos quimiorreceptores periféricos, doença pulmonar sem hipoxemia pela estimulação dos receptores pulmonares ou estimulação direta do centro respiratório, como ocorre em quadros de sepse. Nenhum dos cães do grupo de estudo tinha hipoxemia grave $\left(\mathrm{PO}_{2}<60 \mathrm{~mm} \mathrm{Hg}\right)$. Porém, muitos cães diabéticos sofriam de distúrbios concorrentes (e.g., HAC) que poderiam alterações respiratórias. Em um relato, dos 100 cães diabéticos cujo tórax foi radiografado, 32 apresentavam alterações, como opacificações alveolares e intersticiais, efusão pleural e edema (HESS et al., 2000). Essas condições podem diminuir a complacência pulmonar e causar um defeito restritivo da ventilação pulmonar, resultando em um aumento na excreção do $\mathrm{CO}_{2}$ (DE MORAES; DIBARTOLA, 1999). 
Em um estudo sobre os distúrbios ácido-base em cães com babesiose grave, uma condição similar, i.e., acidose metabólica associada à alcalose respiratória, também foi observada em 32 dos 34 cães estudados. Nesse estudo a $\left[\mathrm{HCO}_{3}{ }^{-}\right]$média foi de $8,3 \mathrm{mmol} / \mathrm{L}$, enquanto a $\mathrm{PCO}_{2}$ média foi igual a 14,4 mm Hg. $\mathrm{A} \mathrm{PCO}_{2}$ foi, aproximadamente, $10 \mathrm{~mm} \mathrm{Hg}$ inferior àquela esperada. Os autores não identificaram a causa para essa alteração (LEISEWITZ et al., 2001).

As diretrizes para o cálculo da compensação esperada dos distúrbios ácido-base em cães são derivadas de estudos experimentais (DE MORAES; DIBARTOLA, 1991). Nesses estudos, a acidose foi induzida pela infusão de ácido clorídrico ou cloreto de amônia até que fosse atingido um estado de equilíbrio e a diminuição da $\mathrm{PCO}_{2}$ ocorreu de modo bastante previsível.

Em um estudo em seres humanos com CAD, sem evidência de condições concomitantes, que poderiam causar distúrbios mistos (“CAD não-complicada”), e pH sangüíneo $>7,10(\mathrm{n}=58)$, aproximadamente $48 \%$ dos pacientes tinham compensação inadequada, segundo as faixas de compensação recomendadas. Desses, 19 (33\%) tinham valores alcalose respiratória e nove (15\%) acidose respiratória (JINN-YUH et al., 1997). Os autores sugeriram que as faixas de compensação de pacientes com CAD possam ser mais amplas do que as recomendadas para pacientes com acidose metabólica crônica e que, mesmo com mais de 24 horas de doença, pacientes com CAD não podem ser considerados como tendo acidose metabólica em equilíbrio.

\subsection{Sobre os distúrbios eletrolíticos}

As concentrações de sódio (mediana: 139,2; variação: 121,7 a 158,6 mmol/L) foram similares às observadas em cães com CAD por Macintire (1993) (média 137 mmol/1; variação: 123 a $152 \mathrm{mmol} / \mathrm{L} ; \mathrm{n}=21$ ). A hiponatremia foi o distúrbio eletrolítico mais 
comum, observado em $67 \%$ dos cães. A hipernatremia foi observada em três pacientes, porém a concentração do sódio nesses pacientes foi $<160 \mathrm{mmoL} / \mathrm{L}$

A hipocloremia também foi comum, ocorrendo em 52\% cães do grupo de estudo. Vale notar que a ocorrência de hipocloremia é menor em relação à de hiponatremia, diferente de outros quadros de perda de fluidos corpóreos, nos quais ocorre uma perda proporcional desses eletrólitos. O papel do cloro, como comentado anteriormente, deve contribuir para a acidose nos cães com CAD. Inexistem estudos sobre os distúrbios do sódio e cloro em cães com CAD. Em um estudo, que avaliou os distúrbios concorrentes de 221 cães com DM (HESS et al., 2000), sem discriminar animais com ou sem cetose, hiponatremia, e hipocloremia foram observadas em $31 \%$ e $60 \%$ dos animais, respectivamente.

A depleção de potássio $\left(\mathrm{K}^{+}\right)$foi comum nos pacientes com CAD (59\%), enquanto, dos animais com $\mathrm{CD}(\mathrm{n}=18), 17$ apresentaram valores de $\mathrm{K}^{+}$normais ou aumentados. Os animais do grupo CD não apresentavam, por definição, êmese ou anorexia, o que explica a menor perda e ingestão adequada. Além disso, a hipoinsulinemia contribui para o desvio do $\mathrm{K}^{+}$, para o liquido extracelular (ADROGUE et al., 1986). Assim, esses animais têm a concentração sérico do $\mathrm{K}^{+}$mantida, embora os estoques corpóreos de $\mathrm{K}^{+}$devam estar diminuídos, em decorrência da diurese osmótica. A hipocalemia também foi um achado freqüente em um estudo de 21 cães com CAD (MACINTIRE, 1993).

A hipofosfatemia não foi observada no presente estudo e a hiperfosfatemia foi observada em aproximadamente $37 \%$ dos cães. A suplementação intravenosa com fosfato de potássio em cães com CAD é, normalmente, recomendada (FELDMAN e NELSON, 2004b). A hipofosfatemia grave em cães e com CAD já foi relatada, porém não é freqüente (WILLARD et al., 1987). Em seres humanos a hiperfosfatemia também é comum na admissão e a hipofosfatemia é um distúrbio que ocorre mais tardiamente, no decurso da terapia e, provavelmente, em pacientes com fósforo inorgânico normal ou diminuído na 
admissão (FISHER; KITABCHI, 1983, KEBLER; MCDONALD; CADNAPAPHORNCHAI, 1985). A suplementação com fosfato de potássio não é isenta de risco, podendo causar hipocalcemia iatrogênica e a recomendação para seu emprego rotineiro deve ser repensada.

A maior parte dos cães apresentou hipocalcemia por ocasião do atendimento inicial (65\%). A hipercalcemia ocorreu em apenas dois pacientes. Na casuística de Hess et al. (2000), 47\% dos cães com DM tinham concentrações diminuídas de $\mathrm{Ca}^{2+}$ (os cães não foram classificados segundo a presença de cetoacidose). A mediana do $\mathrm{Ca}^{2+}$ nos cães hipocalcêmicos foi igual a $1,02 \mathrm{mmol} / \mathrm{L}$, semelhante à observada no presente estudo $(1,14 \mathrm{mmol} / \mathrm{L})$. Assim, estudos futuros seriam pertinentes para elucidar o desenvolvimento da hipocalcemia nos cães com DM, principalmente dos fatores que possam influenciar a fração de cálcio iônico e demais frações do cálcio sérico total (SCHENCK; CHEW, 2003).

Não houve diferença entre as concentrações de magnésio total entre o grupo de estudo e o grupo controle, embora uma parte dos animais com CAD (32\%) apresentasse hipomagnesemia. Acredita-se, entretanto, que o magnésio ionizado plasmático $\left(\mathrm{Mg}^{2+}\right)$ seja um indicador mais específico dos estoques corpóreos do que o magnésio total, a exemplo do que ocorre com o $\mathrm{Ca}^{2+}$.

A ocorrência de hipogmagnesemia foi avaliada em gatos em dois estudos prospectivos. Em um deles, observou-se que o $\mathrm{Mg}^{2+}$ estava diminuído em $61 \%$ dos gatos com CAD na admissão (NORRIS; NELSON; CHRISTOPHER, 1999). No outro estudo, envolvendo gatos com doenças graves, a diminuição do $\mathrm{Mg}^{2+}$ estava associada a um pior prognóstico (TOLL et al., 2002).

Recentemente, a concentração de $\mathrm{Mg}^{2+}$ foi avaliado em 122 cães com DM. Os cães diabéticos foram divididos em grupos semelhantes aos do presente estudo: cães com DM não complicada (DM, n=78 cães), cães com CAD ( $n=32)$, ou cães com CD (n=12) (FINCHAM et al., 2004). As concentrações plasmáticas de $\mathrm{Mg}^{2+}$ foram mais altas em cães com CAD 
(média, 0,41 mmol/L) quando comparadas às de cães com $\mathrm{DM}(0,33 \mathrm{mmol} / \mathrm{L})$ ou com o grupo controle $(0,32 \mathrm{mmol} / \mathrm{L})$. Não houve diferenças significantes entre as concentrações de $\mathrm{Mg}^{2+}$ plasmáticas em cães com $\mathrm{DM}$ ou $\mathrm{CD}$ quando comparados aos cães controle. (FINCHAM et al., 2004).

Os métodos para mensuração das concentrações livres (“ionizadas”) de íons tornaramse mais acessíveis, facilitando a documentação e a monitoração dessas anormalidades eletrolíticas. Concentrações diminuídas de magnésio e cálcio têm sido documentadas em seres humanos com DM tipo 1 e tipo 2 e associadas a muitas complicações clínicas. A hipomagnesemia em cães com CAD parece não ser um distúrbio importante, porém a hipocalcemia é um distúrbio comum em cães com CAD na admissão e sua importância clínica merece atenção.

\subsection{Das limitações do estudo}

Uma das limitações primárias do presente estudo concerne aos critérios adotados para definir CAD e CD. Embora a CAD seja, normalmente, definida como uma tríade composta por hiperglicemia, acidose e cetonemia, não há consenso na literatura veterinária sobre valores específicos para bicarbonato e pH sangüíneo (BRUYETTE, 1997; CRENSHAW e NICHOLS, 1995; FELDMAN e NELSON, 2004b; MACINTIRE, 1993). Optou-se por classificar os animais segundo critérios clínicos, pois, se a definição de CAD fosse baseada estritamente em índices laboratoriais, eventualmente algum animal com distúrbio ácido-base misto -exatamente a população a ser estudada- poderia ser erroneamente classificado. Os achados clinicopatológicos, entretanto, foram bastante semelhantes a outros estudos, nos quais critérios laboratoriais foram utilizados para classificar os pacientes (DUARTE et al., 2002; MACINTIRE, 1993) e, principalmente, são bastante similares aos usados clinicamente. 
Os pacientes não foram submetidos a uma avaliação sistemática e mais ampla para descartar distúrbios mistos. Por exemplo, não foram realizados estudos radiográficos do tórax para excluir doenças pulmonares de todos os cães. O transporte de um paciente em estado crítico a áreas do Hospital cuja monitoração pode ser menos intensiva poderia ser prejudicial. Do mesmo modo, submeter um paciente aparentemente sadio a exames de conveniência, também não foi considerado ético. Os exames complementares foram solicitados a critério do clínico que conduziu o caso.

Não existe um método considerado padrão ("gold standard") para a detecção dos distúrbios mistos, ou mesmo de distúrbios ácido-base simples. A análise dos resultados de hemogasometria são apenas uma das etapas da avaliação de um paciente com suspeita de distúrbios ácido-base. Esses resultados são sempre correlacionados ao quadro clínico e com base no conhecimento da fisiopatogenia das doenças (HALPERIN; GOLDSTEIN, 1999).

Outra limitação importante refere-se ao pequeno número de cães incluídos no grupo de estudo. Muitas das análises envolvendo comparações entre as freqüências de distúrbios podem não ter atingido diferença estatística devido ao número reduzido de animais. 


\section{CONCLUSÃO}

Apesar do pequeno número de animais avaliados, observou-se uma grande variação de distúrbios ácido-base nos cães com cetose ou cetoacidose diabética. O achado de um grande número de pacientes com acidose metabólica normoclorêmica associada com alcalose respiratória é sugestivo de que esse distúrbio pode ser mais freqüente do que o antecipado.

Os distúrbios eletrolíticos de cães com CAD parecem bem caracterizados. Hiponatremia, hipocloremia e hipocalemia são achados freqüentes e devem ser esperados nesses pacientes. As alterações dos distúrbios do fósforo e, principalmente, do $\mathrm{Ca}^{2+}$ merecem maior investigação, a respeito do seu papel na fisiopatogenia da $\mathrm{CAD}$, nas suas complicações e possível implicação no desfecho clínico dos pacientes. 


\section{REFERÊNCIAS ${ }^{1}$}

ADROGUE, H.J.; WILSON, H.; BOYD III, A.E.; SUKI, W.N.; EKNOYAN, G. Plasma acidbase patterns in diabetic ketoacidosis. The New England Journal of Medicine, v. 307, n. 26, p.1603-1610, 1982.

ADROGUÉ, H.J.; EKNOYAN, G.; SUKI, W.K. Diabetic ketoacidosis: Role of the kidney in the acid-base homeostasis re-evaluated. Kidney International, v. 25, n. 4, p. 591-598, 1984.

ADROGUE, H.J.; LEDERER, E.D.; SUKI, W.N.; EKNOYAN, G. Determinants of plasma potassium levels in diabetic ketoacidosis. Medicine (Baltimore), v. 65, n. 3, p. 163-72, 1986.

AMERICAN DIABETES ASSOCIATION. Report of the Expert Committee on the Diagnosis and Classification of Diabetes Mellitus. Diabetes Care, v. 20, n. 7, p. 1183-1197, 1997

AMERICAN DIABETES ASSOCIATION. Hyperglycemic Crises in Diabetes. Diabetes Care, v. 27, p. S94-S102. 2004. Suplemento 1.

BELL, D.S.H.; ALELE, J. Diabetic ketoacidosis: why early detection and aggressive treatment are crucial. Posgraduate Medicine, v. 101, n. 4, p. 193-204, 1997.

BRUYETTE, D.S. Diabetic ketoacidosis. Seminars in Veterinary Medicine and Surgery (Small Animal), v. 12, n. 4, p. 239-247, 1997.

CRENSHAW, K.L.; NICHOLS, R. Complications and concurrent disease associated with diabetic ketoacidosis and other severe forms of diabetes mellitus. The Veterinary Clinics of North America (Small Animal Practice), v. 25, n. 3, p. 617-624, 1995.

DE MORAIS, H.A. Disorders of chloride. In: DIBARTOLA, S.P. Fluid therapy in small animal practice. 2 ed. Philadelphia, W.B. Saunders, 1999, p. 83-107.

DE MORAIS, H.A.; DIBARTOLA, S.P. Ventilatory and metabolic compensation in dogs with acid-base disturbances. Veterinary Emergency and Critical Care, vol. 1, n. 2, p. 3949, 1991

DE MORAIS, H.A.; DIBARTOLA, S.P. Mixed acid-base disorders. In: DIBARTOLA, S.P. Fluid therapy in small animal practice. 2 ed. Philadelphia, W.B. Saunders, 1999, p. 251264.

\footnotetext{
${ }^{1}$ Conforme as Diretrizes para apresentação de dissertações e teses na Faculdade de Medicina Veterinária e Zootecnia da Universidade de São Paulo. 4. ed. rev. atual. e ampl. São Paulo: FMVZ-USP, 2003. 84 p.
} 
DIBARTOLA, S.P. Introduction to acid-base disorders. In: animal practice. 2 ed. Philadelphia, W.B. Saunders, 1999b, p. 189-210.

Fluid therapy in small

DIBARTOLA, S.P. Metabolic acid-base disorders disorders. In: small animal practice. 2 ed. Philadelphia, W.B. Saunders, 1999a, p. 21 $1-239$.

Fluid therapy in

DUARTE, R.; SIMÕES, D.M.; FRANCHINI, M.L.; MARQUEZI, M.L.; IKESAKI, J.H.; KOGIKA, MM. Accuracy of serum beta-hydroxybutyrate measurements for the diagnosis of diabetic ketoacidosis in 116 dogs. Journal of Veterinary Internal Medicine, v. 16, n. 4, p. 411-417, 2002.

FELDMAN, E.C.; NELSON, R.W. Canine diabetes mellitus. In: Canine and feline endocrinology and reproduction. 3 ed. Philadelphia: WB Saunders, 2004a. p. 486-538.

FELDMAN, E.C.; NELSON, R.W. Diabetic ketoacidosis In: Canine and feline endocrinology and reproduction. 3 ed. Philadelphia: WB Saunders, 2004a. p. 580-615.

FINCHAM, S.C.; DROBATZ, K.J.; GILLESPIE, T.N.; HESS, R.S. Evaluation of plasmaionized magnesium concentration in 122 dogs with diabetes mellitus: a retrospective study. Journal of Veterinary Internal Medicine, v. 18, n. 5, p. 612-617, 2004.

FISHER, J.N.; KITABCHI, A.E. A randomized study of phosphate therapy in the treatment of diabetic ketoacidosis. Journal of Clinical and Endocrinology Metabolism, v. 57, n. 1, p. 177-180, 1983.

HALPERIN, M.L.; GOLDSTEIN, M.B. The clinical approach to acid-base disorders. In: Fluid, electrolyte, and acid-base physiology: a problem-based approach, $3 \mathrm{ed}$. Philadelphia: WB Saunders, 1999. p. 49-72.

HESS, R.S.; SAUNDERS, H.M.; VAN WINKLE, T.J.; WARD, C.R. Concurrent disorders in dogs with diabetes mellitus: 221 cases (1993-1998). Journal of the American Veterinary Medical Association, v. 217, n. 8, p. 1166-1173, 2000.

JINN-YUH, G.; YUNG-HSIUNG, L.; LAI-KING, Y.; SHYI-JANG, S.; JUEI-HSIUNG, T. Evaluation of ventilatory responses in severe acidemia in diabetic ketoacidosis. American Journal of Nephrology, v. 17, n. 1, p. 36-41, 1997.

KEBLER, R.; MCDONALD, F.D.;CADNAPAPHORNCHAI, P. Dynamic changes in serum phosphorus levels in diabetic ketoacidosis. American Journal of Medicine, v. 79, n. 5, p. 571-576, 1985. 
KITABCHI, A.E.; UMPIERREZ, G.E.; MURPHY, M.B.; BARRETT, E.J.; KREISBERG, R.A.; MALONE, J.I.; WALL, B.M. Management of hyperglycemic crises in patients with diabetes. Diabetes Care, v. 24, n. 1, p. 131-153, 2001.

LAFFEL, L. Ketone bodies: a review of physiology, pathophysiology and application of monitoring to diabetes. Diabetes/Metabolism: Research and Reviews, v. 15, n. 6, p. 412426, 1999.

LEISEWITZ, A.L.; JACOBSON, L.S.; DE MORAIS, H.S.; REYERS, F. The mixed acidbase disturbances of severe canine babesiosis. Journal of Veterinary Internal Medicine, v. 15, n. 5 , p. $445-452,2001$.

MACINTIRE, D.K. Treatment of diabetic ketoacidosis in dogs by continuous low-dose intravenous infusion of insulin. Journal of the American Veterinary Medical Association, v. 202, n. 8, p. 1266-1272, 1993.

MARMOR, M.; WILLEBERG, P.; GLICKMAN, L.T.; PRIESTER, W.A.; CYPESS, R.H.; HURVITZ, A.I. Epizootiologic paterns of diabetes mellitus in dogs. American Journal of Veterinary Research, v. 43, n. 3, p. 465-470, 1982.

NORRIS, C.R.; NELSON, R.W.; CHRISTOPHER, M.M. Serum total and ionized magnesium concentrations and urinary fractional excretion of magnesium in cats with diabetes mellitus and diabetic ketoacidosis. Journal of the American Veterinary Medical Association, v. 215, n. 10, p. 1455-1459, 1999.

OKUDA, Y.; ADROGUE, H.J.; FIELD, J.B.; NOHARA, H.; YAMASHITA, K. Counterproductive effects of sodium bicarbonate in diabetic ketoacidosis. Journal of Clinical Endocrinology and Metabolism, v. 81, n. 1, p. 314-320, 1996.

PAULSON, W.D.; GADALLAH, M.F. Diagnosis of mixed acid-base disorders in diabetic ketoacidosis. The American Journal of the Medical Sciences, v. 306, n. 5, p. 295-300, 1993.

SCHENCK, P.A.; CHEW, D.J. Determination of calcium fractionation in dogs with chronic renal failure. American Journal of Veterinary Research, v. 64, n. 6, p. 1181-1184, 2003.

TOLL, J.; ERB, H.; BIRNBAUM, N.; SCHERMERHORN, T. Prevalence and incidence of serum magnesium abnormalities in hospitalized cats. Journal of Veterinary Internal Medicine, v. 16, n. 3, p. 217-221, 2002. 
WILLARD, M.D.; ZERBE, C.A.; SCHALL, W.D.; JOHNSON, C.; CROW, S.E. Severe hypophosphatemia associated with diabetes mellitus in six dogs and one cat. Journal of the American Veterinary Medical Association, v. 190, n. 8, p. 1007-1010, 1987. 
APÊNDICE A - Características dos cães incluídos no subgrupo cetoacidose diabética (CAD).

\begin{tabular}{ccccccccc}
\hline Data & Prontuário & Nome & Raça & Sexo & $\begin{array}{c}\text { Idade } \\
\text { (anos) }\end{array}$ & $\begin{array}{c}\text { Peso } \\
\text { (kg) }\end{array}$ & Queixa principal & $\underline{\text { R }}$ x \\
\hline $25 / 7 / 2005$ & 164407 & Madona & Rottweiler & F & 5 & 30,8 & Emese & RD \\
$13 / 6 / 2005$ & 114315 & Kika & SRD & F & 18 & 4,8 & Anorexia & IT \\
$29 / 4 / 2005$ & 118067 & Kika & Dobermann & F & 12 & 26,5 & Letargia & IT \\
$15 / 4 / 2005$ & 149789 & Priscila & Husky siberiano & FC & 7 & 21 & Emese & IT \\
$24 / 3 / 2005$ & 160847 & Jade & Rottweiler & F & 5 & 37,4 & Disorexia & IT \\
$3 / 3 / 2005$ & 144472 & Pitt & Poodle & FC & 10 & 13,5 & Emese & IT \\
$2 / 2 / 2005$ & 159258 & Rudy & Poodle & M & 5 & 5,8 & Letargia & RD \\
$22 / 12 / 2004$ & 139589 & Buba & SRD & FC & 12 & 6,8 & Letargia & IT \\
$16 / 12 / 2004$ & 158029 & Kika & Terrier Brasileiro & F & 14 & 5,6 & Emese & IT \\
$13 / 12 / 2004$ & 157915 & Hawa & Rottweiler & F & 11 & 30,0 & Disorexia & RD \\
$26 / 11 / 2004$ & 157466 & Bob & Poodle & M & 5 & 5,0 & Anorexia & RD \\
$23 / 9 / 2004$ & 155571 & Luppy & Poodle & M & 5 & 12,2 & Emese & RD \\
$2 / 9 / 2004$ & 142817 & Pepita & SRD & F & 10 & 10,0 & Anorexia & NOD \\
$5 / 1 / 2004$ & 147167 & Preta & SRD & F & 13 & 20,0 & Emese & IT \\
$8 / 12 / 2003$ & 148289 & Billy & SRD & F & 15 & 7,6 & Anorexia & RD \\
$27 / 11 / 2003$ & 148058 & Bolinha & SRD & FC & 11 & 18,7 & Anorexia & RD \\
$19 / 11 / 2003$ & 147819 & Pity & Poodle Miniatura & M & 9 & 11,6 & Emese & RD \\
$3 / 10 / 2003$ & 146558 & Xuxa & Poodle Minitura & F & 10 & 5,9 & Disorexia & RD \\
$27 / 8 / 2003$ & 145401 & Bride & Poodle & F & 16 & 5,7 & Disorexia & RD \\
$18 / 8 / 2003$ & 145122 & Nick & SRD & M & 8 & 26,8 & Emese & IT \\
$16 / 5 / 2003$ & 142252 & Rebeca & SRD & F & 10 & 8,0 & Disorexia & RD \\
$1 / 6 / 2005$ & 161127 & Billy & SRD & FC & 10 & 13,7 & Anorexia & IT \\
\hline
\end{tabular}

APÊNDICE B - Características dos cães incluídos no subgrupo cetose diabética (CD).

\begin{tabular}{|c|c|c|c|c|c|c|c|c|}
\hline Data & Prontuário & Nome & Raça & Sexo & $\begin{array}{l}\text { Idade } \\
\text { (anos) }\end{array}$ & $\begin{array}{l}\text { Peso } \\
(k g)\end{array}$ & Queixa principal & $\underline{\mathbf{R}}_{\underline{x}}$ \\
\hline $25 / 7 / 2005$ & 164375 & Zima & Pastor Alemão & $\mathrm{FC}$ & 8 & 30,5 & Mau controle & IT \\
\hline $6 / 7 / 2005$ & 163752 & Dinho & SRD & M & 10 & 31,8 & Paralisia facial & $\mathrm{RD}$ \\
\hline $15 / 6 / 2005$ & 107955 & Xuxa & Poodle & $\mathrm{F}$ & 9 & 4,2 & Poliúria/polidipsia & $\mathrm{RD}$ \\
\hline $25 / 5 / 2005$ & 155876 & Dolly & Beagle & $\mathrm{FC}$ & 8 & 12,4 & Poliúria/polidipsia & IT \\
\hline $18 / 1 / 2005$ & 93842 & Taty & SRD & $\mathrm{F}$ & 15 & 7,2 & Abscesso em mama & IT \\
\hline $2 / 12 / 2004$ & 81087 & Laika & SRD & $\mathrm{F}$ & 11 & 17,6 & Mau controle & IT \\
\hline $26 / 11 / 2004$ & 149849 & Serena & Poodle & $\mathrm{F}$ & 8 & 7,7 & Poliúria/polidipsia & $\mathrm{RD}$ \\
\hline $19 / 10 / 2004$ & 156302 & Cockie & Poodle & M & 12 & 5,0 & Catarata & $\mathrm{RD}$ \\
\hline $24 / 6 / 2004$ & 153292 & Tapiti & Fox P & M & 8,3 & 12,0 & Poliúria/polidipsia & IT \\
\hline $19 / 11 / 2003$ & 145668 & Baby & SRD & $\mathrm{F}$ & 13 & 17,0 & Poliúria/polidipsia & IT \\
\hline $5 / 11 / 2003$ & 147339 & Teca & SRD & $\mathrm{FC}$ & 9 & 10,2 & Emagrecimento & $\mathrm{RD}$ \\
\hline $19 / 9 / 2003$ & 146095 & Pepita & Dálmata & $\mathrm{F}$ & 13 & 16,1 & Emagrecimento & $\mathrm{RD}$ \\
\hline 9/9/2003 & 139851 & Pingo & Poodle Toy & M & 7 & 4,2 & $\begin{array}{c}\text { Poliúria/polidipsia/perda } \\
\text { de peso/ polifagia }\end{array}$ & $\mathrm{RD}$ \\
\hline $8 / 8 / 2003$ & 57017 & Buchucha & Terrier Brasileiro & $\mathrm{FC}$ & 13 & 6,5 & $\begin{array}{c}\text { Poliúria/polidipsia/perda } \\
\text { de peso/ polifagia }\end{array}$ & IT \\
\hline $13 / 6 / 2003$ & 52122 & Diny & SRD & $\mathrm{F}$ & 8 & 5,7 & Catarata & $\mathrm{RD}$ \\
\hline $10 / 4 / 2003$ & 141295 & Suzy & Poodle Miniatura & $\mathrm{F}$ & 10 & 5,1 & $\begin{array}{l}\text { Poliúria/polidipsia/perda } \\
\text { de peso/ polifagia }\end{array}$ & RD \\
\hline $2 / 4 / 2003$ & 141069 & Nina & SRD & $\mathrm{FC}$ & 8 & 16,0 & Catarata & $\mathrm{RD}$ \\
\hline $21 / 3 / 2003$ & 140710 & Camila & Beagle & $\mathrm{F}$ & 8 & 6,0 & Emagrecimento & IT \\
\hline
\end{tabular}

SRD: sem raça definida; F: fêmea; FC: fêmea castrada; M: macho; $\underline{R}_{x}$ : tratamento RD: recém diagnosticado; IT: em insulinoterapia. 
APÊNDICE C - Avaliação da homocedastidade e diferenças entre os subgrupos de estudo por análise de variância (ANOVA) e pelo teste não-paramétrico de MannWhitney das variáveis de estudo.

\begin{tabular}{|c|c|c|c|c|c|c|c|c|c|}
\hline & Grupo & $\mathbf{N}$ & Média & DP & Mínimo & Máximo & Homocedastidade & ANOVA & Mann-Whitney \\
\hline & & & & & & & \multicolumn{3}{|c|}{ Nível Descritivo $(P)$} \\
\hline \multirow[t]{3}{*}{$\mathrm{pH}$} & CAD & 22 & 7,241 & 0,124 & 7,001 & 7,487 & 0,001 & 0,000 & 0,000 \\
\hline & CD & 18 & 7,394 & 0,049 & 7,267 & 7,459 & & & \\
\hline & Total & 40 & 7,310 & 0,123 & 7,001 & 7,487 & & & \\
\hline \multirow[t]{3}{*}{$\mathrm{PCO}_{2}$} & CAD & 22 & 22,2 & 4,486 & 13,90 & 29,5 & 0,499 & 0,000 & 0,001 \\
\hline & $\mathrm{CD}$ & 18 & 28,5 & 5,822 & 14,20 & 38,2 & & & \\
\hline & Total & 40 & 25,0 & 5,984 & 13,90 & 38,2 & & & \\
\hline \multirow[t]{3}{*}{$\mathrm{PO}_{2}$} & CAD & 22 & 119 & 50 & 72,1 & 299,9 & 0,053 & 0,022 & 0,001 \\
\hline & $\mathrm{CD}$ & 18 & 89 & 17 & 69,6 & 147,0 & & & \\
\hline & Total & 40 & 105 & 41 & 69,6 & 299,9 & & & \\
\hline \multirow[t]{3}{*}[\mathrm{HCO}_{3}]{} & CAD & 22 & 9,64 & 3,68 & 5,30 & 17,3 & 0,417 & 0,000 & 0,000 \\
\hline & CD & 18 & 16,92 & 3,75 & 6,20 & 22,3 & & & \\
\hline & Total & 40 & 12,92 & 5,18 & 5,30 & 22,3 & & & \\
\hline \multirow[t]{3}{*}{$\mathrm{BE}$} & CAD & 22 & $(15,25)$ & 5,58 & $(24,4)$ & $(3,1)$ & 0,017 & 0,000 & 0,000 \\
\hline & $\mathrm{CD}$ & 18 & $(5,85)$ & 3,70 & $(17,2)$ & $(0,4)$ & & & \\
\hline & Total & 40 & $(11,02)$ & 6,72 & $(24,4)$ & $(0,4)$ & & & \\
\hline \multirow[t]{3}{*}{$\mathrm{SO}_{2}$} & CAD & 22 & 95,314 & 2,90 & 88,2 & 99,9 & 0,198 & 0,948 & 0,861 \\
\hline & $\mathrm{CD}$ & 18 & 95,261 & 1,99 & 91,7 & 98,4 & & & \\
\hline & Total & 40 & 95,290 & 2,50 & 88,2 & 99,9 & & & \\
\hline \multirow[t]{3}{*}{$\mathrm{Na}^{+}$} & CAD & 22 & 139,6 & 8,74 & 121,7 & 158,6 & 0,205 & 0,905 & 0,904 \\
\hline & $\mathrm{CD}$ & 18 & 139,928 & 5,668 & 131,7 & 154,3 & & & \\
\hline & Total & 40 & 139,770 & 7,427 & 121,7 & 158,6 & & & \\
\hline \multirow[t]{3}{*}{$\mathrm{K}^{+}$} & CAD & 22 & 3,515 & 0,749 & 2,30 & 5,01 & 0,754 & 0,000 & 0,000 \\
\hline & CD & 18 & 4,472 & 0,775 & 2,85 & 5,77 & & & \\
\hline & Total & 40 & 3,946 & 0,893 & 2,30 & 5,77 & & & \\
\hline \multirow[t]{3}{*}{$\mathrm{Ca}^{2+}$} & CAD & 22 & 1,159 & 0,179 & 0,741 & 1,613 & 0,484 & 0,586 & 0,778 \\
\hline & $\mathrm{CD}$ & 18 & 1,206 & 0,348 & 0,827 & 2,489 & & & \\
\hline & Total & 40 & 1,180 & 0,266 & 0,741 & 2,489 & & & \\
\hline \multirow[t]{3}{*}{$\mathrm{Cl}^{-}$} & CAD & 22 & 104,695 & 10,565 & 82,7 & 126,4 & 0,205 & 0,963 & 0,968 \\
\hline & $\mathrm{CD}$ & 18 & 104,561 & 6,802 & 90,7 & 118,6 & & & \\
\hline & Total & 40 & 104,635 & 8,960 & 82,7 & 126,4 & & & \\
\hline \multirow[t]{3}{*}{$\mathrm{Mg}$} & CAD & 22 & 2,305 & 0,682 & 1,2 & 3,7 & 0,031 & 0,184 & 0,396 \\
\hline & $\mathrm{CD}$ & 18 & 2,063 & 0,357 & 1,3 & 2,6 & & & \\
\hline & Total & 40 & 2,196 & 0,566 & 1,2 & 3,7 & & & \\
\hline \multirow[t]{3}{*}{ AG } & CAD & 22 & 28,815 & 7,737 & 13,9 & 43,77 & 0,135 & 0,011 & 0,008 \\
\hline & $\mathrm{CD}$ & 18 & 22,917 & 5,838 & 10,6 & 31,76 & & & \\
\hline & Total & 40 & 26,161 & 7,478 & 10,6 & 43,77 & & & \\
\hline \multirow[t]{3}{*}{ Gli } & CAD & 22 & 550 & 320 & 273 & 1670 & 0,248 & 0,673 & 0,619 \\
\hline & $\mathrm{CD}$ & 18 & 515 & 152 & 341 & 750 & & & \\
\hline & Total & 40 & 534 & 256 & 273 & 1.670 & & & \\
\hline \multirow[t]{3}{*}{ Uréia } & CAD & 22 & 85 & 71 & 17 & 304 & 0,018 & 0,050 & 0,079 \\
\hline & $\mathrm{CD}$ & 18 & 47 & 40 & 22 & 199 & & & \\
\hline & Total & 40 & 68,254 & 61,542 & 17 & 304 & & & \\
\hline \multirow[t]{3}{*}{$\mathrm{Pi}$} & CAD & 22 & 6,480 & 2,054 & 3,28 & 10,85 & 0,147 & 0,897 & 0,946 \\
\hline & CD & 18 & 6,405 & 1,409 & 4,03 & 9,27 & & & \\
\hline & Total & 40 & 6,446 & 1,771 & 3,28 & 10,85 & & & \\
\hline
\end{tabular}


APÊNDICE C - continuação

\begin{tabular}{cccccccccc}
\hline & Grupo & N & Média & DP & Mínimo & Máximo & Homocedastidade & ANOVA & Mann-Whitney \\
\hline \multirow{3}{*}{$\beta$-HOB } & & & & & & & & Nível Descritivo(P) \\
& CAD & 22 & 6,390 & 2,35 & 3,06 & 10,54 & 0,099 & 0,000 & 0,000 \\
& CD & 18 & 3,064 & 1,90 & 0,06 & 7,66 & & \\
& Total & 40 & 4,894 & 2,71 & 0,06 & 10,54 & & \\
\hline
\end{tabular}

$\mathrm{PCO}_{2}$ : pressão parcial de dióxido de carbono; $\mathrm{PO}_{2}$ : pressão parcial de oxigênio; $\left[\mathrm{HCO}_{3}\right]$ : concentração plasmática do bicarbonato; $\mathrm{BE}$ : déficit de base; $\mathrm{SO}_{2}$ saturação sangüínea de oxigênio. $\mathrm{Na}^{+}$: sódio plasmático; $\mathrm{K}^{+}$: potássio plasmático; $\mathrm{Ca}^{2+}$ : cálcio ionizado plasmático; $\mathrm{Cl}^{-}$: Cloro plasmático; $\mathrm{Mg}$ : magnésio total sérico; AG: anion gap; Gli: glicemia; Uréia: uréia sérica; Pi: fósforo inorgânico sérico; $\beta$-HOB: $\beta$-hidroxibutirato sérico. 
APÊNDICE D - Valores da determinação do pH, hemogasometria, déficit de base, temperatura corpórea, eletrólitos e bioquímica sérica dos cães incluídos no subgrupo cetoacidose diabética (CAD).

\begin{tabular}{|c|c|c|c|c|c|c|c|c|c|c|c|c|c|c|c|c|c|}
\hline Prontuário & $\mathrm{pH}$ & $\mathrm{PCO}_{2}$ & $\mathrm{PO}_{2}$ & $\mathrm{HCO}_{3}$ & $\mathrm{BE}$ & $\mathrm{SO}_{2}$ & $\mathrm{~T}^{\circ} \mathrm{C}$ & $\mathrm{Na}^{+}$ & $\mathrm{K}^{+}$ & $\mathrm{Ca}^{2+}$ & $\mathrm{Cl}^{-}$ & $\mathrm{Mg}$ & AG & Gli & Uréia & $\mathrm{Pi}$ & $\beta$-HOB \\
\hline 164407 & 7,001 & 22,9 & 101,5 & 5,5 & $-24,4$ & 90,7 & 37,2 & 141,8 & 3,41 & 1,285 & 104,1 & 3,7 & 35,6 & 1150 & 228 & 8,45 & 7,2 \\
\hline 114315 & 7,318 & 25,5 & 102,2 & 12,7 & $-11,2$ & 96,6 & 37,7 & 138,5 & 5,01 & 1,104 & 105,4 & 2,9 & 25,4 & 557 & 105 & 4,80 & 4,9 \\
\hline 118067 & 7,195 & 14,4 & 111,2 & 5,3 & $-19,4$ & 95,0 & 39,2 & 139,0 & 3,31 & 1,335 & 104,2 & 1,9 & 32,8 & 414 & 46 & 7,37 & 7,1 \\
\hline 149789 & 7,487 & 23,8 & 96,9 & 17,3 & $-3,1$ & 97,3 & 39,3 & 139,6 & 4,78 & 1,116 & 103,3 & 2,4 & 23,8 & 340 & 27 & 7,90 & 3,6 \\
\hline 160847 & 7,362 & 22,2 & 94,9 & 12,1 & $-10,4$ & 95,9 & 38,7 & 146,5 & 2,61 & 1,370 & 113,8 & 1,2 & 23,2 & 362 & 17 & 3,28 & 3,4 \\
\hline 144472 & 7,427 & 19,2 & 72,1 & 12,2 & $-8,9$ & 93,3 & 38,2 & 136,6 & 3,20 & 1,125 & 95,4 & 3,4 & 32,2 & 609 & 66 & 5,99 & 5,2 \\
\hline 158029 & 7,084 & 22,9 & 109,2 & 6,5 & $-21,2$ & 93,0 & 38,6 & 146,4 & 3,31 & 1,070 & 110,5 & 1,9 & 32,7 & 643 & 101 & 10,85 & 10,1 \\
\hline 157915 & 7,264 & 28,7 & 135,5 & 12,5 & $-12,3$ & 98,1 & 38,5 & 132,9 & 3,48 & 1,136 & 109,9 & 1,7 & 14,0 & 490 & 26 & 6,37 & 4,4 \\
\hline 157466 & 7,275 & 20,2 & 141,6 & 9,0 & $-14,8$ & 98,3 & 38,7 & 140,0 & 2,30 & 0,966 & 118,6 & 2,4 & 14,7 & 273 & 27 & 4,05 & 5,5 \\
\hline 155571 & 7,164 & 25,8 & 114,5 & 8,9 & $-17,6$ & 95,6 & 38,2 & 121,7 & 3,45 & 0,741 & 82,7 & 3,5 & 33,6 & 1670 & 304 & 9,66 & 3,5 \\
\hline 142817 & 7,078 & 21,5 & 98,9 & 6,1 & $-21,9$ & 91,4 & 37,9 & 129,4 & 3,21 & 1,206 & 104,0 & 3,2 & 22,5 & 320 & 118 & 3,62 & 7,2 \\
\hline 146558 & 7,378 & 20,7 & 299,9 & 11,8 & $-10,4$ & 99,9 & 38,3 & 155,3 & 4,04 & 1,054 & 126,4 & 2,2 & 21,1 & 494 & 54 & 5,51 & 4,8 \\
\hline 145401 & 7,296 & 29,5 & 85,1 & 14,0 & $-10,9$ & 94,5 & 37,0 & 148,0 & 3,20 & 1,092 & 102,9 & 2,5 & 34,3 & 485 & 136 & 5,80 & 7,8 \\
\hline 145122 & 7,198 & 24,7 & 78,5 & 9,2 & $-16,5$ & 88,2 & 38,6 & 145,5 & 3,65 & 1,114 & 105,8 & 2,1 & 34,2 & 344 & 63 & 6,24 & 7,6 \\
\hline 142252 & 7,366 & 29,3 & 85,9 & 16,1 & $-7,1$ & 94,9 & 38,5 & 139,4 & 4,47 & 0,927 & 98,0 & 1,4 & 29,8 & 396 & 56 & 8,58 & 8,1 \\
\hline 161127 & 7,209 & 13,9 & 113,1 & 5,4 & $-19,5$ & 96,3 & 37,6 & 125,0 & 3,00 & 1,159 & 87,0 & 2,0 & 35,6 & 375 & 104 & 8,84 & 3,1 \\
\hline
\end{tabular}

$\mathrm{PCO}_{2}$ : pressão parcial de dióxido de carbono; $\mathrm{PO}_{2}$ : pressão parcial de oxigênio; $\left[\mathrm{HCO}_{3}\right]$ : concentração plasmática do bicarbonato; $\mathrm{BE}$ : déficit de base; $\mathrm{SO}_{2}$ saturação sangüínea de oxigênio. $\mathrm{T}^{\circ} \mathrm{C}$ : temperatura corpórea em graus Celsius; $\mathrm{Na}^{+}$: sódio plasmático; $\mathrm{K}^{+}$: potássio plasmático; $\mathrm{Ca}^{2+}$ : cálcio ionizado plasmático; $\mathrm{Cl}$ : Cloro plasmático; $\mathrm{Mg}$ : magnésio total sérico; AG: anion gap; Gli: glicemia; Uréia: uréia sérica; Pi: fósforo inorgânico sérico; $\beta$-HOB: $\beta$-hidroxibutirato sérico. 
APÊNDICE E - Valores da determinação do pH, hemogasometria, déficit de base, temperatura corpórea, eletrólitos e bioquímica sérica dos cães incluídos no subgrupo cetose diabética (CD).

\begin{tabular}{|c|c|c|c|c|c|c|c|c|c|c|c|c|c|c|c|c|c|}
\hline prontuário & $\mathrm{pH}$ & $\mathrm{PCO}_{2}$ & $\mathrm{PO}_{2}$ & $\mathrm{HCO}_{3}$ & $\mathrm{BE}$ & $\mathrm{SO}_{2}$ & $T^{\circ} \mathrm{C}$ & $\mathrm{Na}^{+}$ & $\mathrm{K}^{+}$ & $\mathrm{Ca}^{2+}$ & $\mathrm{Cl}^{-}$ & $\mathbf{M g}$ & $\mathbf{A G}$ & Gli & Uréia & $\mathrm{Pi}$ & $\beta$-HOB \\
\hline 164375 & 7,424 & 27,7 & 104,8 & 17,3 & $-4,4$ & 97,2 & 39,8 & 138,0 & 4,70 & 1,198 & 103,6 & 2,3 & 21,8 & 706 & 26 & 4,99 & 1,9 \\
\hline 163752 & 7,388 & 38,2 & 69,6 & 22,2 & $-1,8$ & 91,7 & 38,6 & 144,1 & 4,18 & 1,299 & 101,3 & 1,6 & 24,8 & 712 & 41 & 4,03 & 2,7 \\
\hline 107955 & 7,341 & 29,4 & 82,6 & 15,2 & $-8,2$ & 93,0 & 38,0 & 148,6 & 4,63 & 1,113 & 109,8 & 1,6 & 28,2 & 402 & 28 & 8,00 & 3,4 \\
\hline 155876 & 7,430 & 21,4 & 103,0 & 13,6 & $-7,5$ & 97,4 & 38,7 & 134,1 & 4,52 & 1,141 & 100,5 & 2,0 & 24,5 & 694 & 56 & 4,76 & 1,1 \\
\hline 93842 & 7,365 & 31,6 & 75,8 & 17,2 & $-5,9$ & 91,7 & 39,5 & 142,1 & 3,60 & 1,253 & 106,6 & 2,4 & 21,9 & 344 & 199 & 7,84 & 0,1 \\
\hline 81087 & 7,446 & 21,9 & 94,0 & 14,5 & $-6,2$ & 96,4 & 39,6 & 137,7 & 3,75 & 1,154 & 110,6 & 2,0 & 16,4 & 341 & 41 & 4,49 & 4,2 \\
\hline 153292 & 7,333 & 33,1 & 90,3 & 17,1 & $-7,4$ & 95,6 & 37,7 & 132,9 & 5,77 & 1,256 & 111,0 & 2,2 & 10,6 & 636 & 41 & 5,78 & 1,3 \\
\hline 145668 & 7,408 & 34,0 & 80,3 & 20,6 & $-2,5$ & 94,6 & 38,7 & 141,9 & 4,11 & 1,279 & 107,3 & 2,3 & 18,1 & 449 & 44 & 6,05 & 2,4 \\
\hline 147339 & 7,410 & 32,5 & 85,7 & 20,0 & $-3,2$ & 95,8 & 38,2 & 137,5 & 4,36 & 1,239 & 105,0 & 1,5 & 16,9 & 350 & 29 & 7,59 & 3,3 \\
\hline 146095 & 7,459 & 27,5 & 91,5 & 18,7 & $-2,7$ & 96,7 & 39,0 & 135,1 & 5,38 & 0,956 & 90,7 & 1,3 & 31,1 & 548 & 61 & 6,60 & 3,1 \\
\hline 139851 & 7,365 & 28,5 & 82,5 & 15,8 & $-7,7$ & 94,8 & 37,8 & 142,1 & 3,76 & 0,853 & 102,0 & 2,0 & 28,1 & 360 & 22 & 6,24 & 7,7 \\
\hline 141069 & 7,418 & 28,8 & 89,3 & 18,0 & $-4,6$ & 96,3 & 37,0 & 141,1 & 4,87 & 1,220 & 104,6 & 2,0 & 23,4 & 378 & 29 & 6,55 & 3,5 \\
\hline 140710 & 7,344 & 32,8 & 74,1 & 17,3 & $-6,9$ & 92,3 & 38,9 & 131,7 & 4,90 & 1,117 & 96,9 & 2,1 & 22,4 & 534 & 55 & 7,11 & 4,4 \\
\hline
\end{tabular}

$\mathrm{PCO}_{2}$ : pressão parcial de dióxido de carbono; $\mathrm{PO}_{2}$ : pressão parcial de oxigênio; $\left[\mathrm{HCO}_{3}\right]$ : concentração plasmática do bicarbonato; $\mathrm{BE}$ : déficit de base; $\mathrm{SO}_{2}$ saturação sangüínea de oxigênio. $\mathrm{T}^{\circ} \mathrm{C}$ : temperatura corpórea em graus Celsius; $\mathrm{Na}^{+}$: sódio plasmático; $\mathrm{K}^{+}$: potássio plasmático; $\mathrm{Ca}^{2+}$ : cálcio ionizado plasmático; $\mathrm{Cl}$ : Cloro plasmático; $\mathrm{Mg}$ : magnésio total sérico; AG: anion gap; Gli: glicemia; Uréia: uréia sérica; Pi: fósforo inorgânico sérico; $\beta$-HOB: $\beta$-hidroxibutirato sérico. 
APÊNDICE F - Características e valores da hemogasometria dos cães clinicamente hígidos incluídos no grupo controle.

\begin{tabular}{|c|c|c|c|c|c|c|c|c|c|}
\hline nome & raça & sexo & idade & pH & $\mathrm{PCO}_{2}$ & $\mathrm{PO}_{2}$ & $\mathrm{HCO}_{3}$ & BE & $\mathrm{SO}_{2}$ \\
\hline Cipó & SRD & $\bar{M}$ & 7 & 7,442 & 31,5 & 98,0 & 20,7 & $-1,7$ & 97,3 \\
\hline Pituca & SRD & $\mathrm{F}$ & 15 & 7,438 & 37,2 & 94,6 & 24,2 & 0,9 & 97,1 \\
\hline Paty & Poodle & $\mathrm{F}$ & 8 & 7,464 & 26,3 & 104,1 & 28,2 & $-3,2$ & 97,9 \\
\hline Astor & PA & M & 7 & 7,482 & 25,3 & 103,5 & 18,2 & $-2,6$ & 97,9 \\
\hline Lupy & Poodle & M & 4 & 7,423 & 35,2 & 79,4 & 22,0 & $-0,8$ & 94,1 \\
\hline Satine & West & $\mathrm{F}$ & 3 & 7,426 & 35,4 & 113,3 & 22,2 & $-0,5$ & 97,9 \\
\hline Gull & Bull T & $\mathrm{F}$ & 3 & 7,406 & 38,7 & 108,4 & 23,2 & $-0,3$ & 97,6 \\
\hline Higor & Border & M & 2 & 7,390 & 36,5 & 85,0 & 21,0 & $-2,3$ & 94,5 \\
\hline Bob & Cocker & M & 7 & 7,416 & 27,8 & 119,0 & 17,2 & $-5,0$ & 98,2 \\
\hline Melissa & Cocker & $\mathrm{F}$ & 0,65 & 7,432 & 33,0 & 93,9 & 21,1 & $-1,5$ & 96,7 \\
\hline Atila & SRD & M & & 7,424 & 32,9 & 97,9 & 20,7 & $-2,0$ & 97,0 \\
\hline Melissia & Golden & $\mathrm{F}$ & 0,8 & 7,416 & 35,5 & 89,2 & 22,0 & $-1,3$ & 96,2 \\
\hline Juca & Bull T & M & 1,5 & 7,424 & 37,9 & 96,4 & 23,7 & 0,5 & 96,7 \\
\hline Barney & Poode & M & 7 & 7,451 & 30,4 & 89,5 & 20,4 & $-1,7$ & 96,5 \\
\hline Jane & Cocker & $\mathrm{F}$ & 8 & 7,471 & 24,1 & 110,1 & 17,0 & $-4,0$ & 98,3 \\
\hline Lola & Dachs & $\mathrm{F}$ & 5 & 7,436 & 27,6 & 100,9 & 17,8 & $-3,8$ & 97,0 \\
\hline Shaila & Boxer & $\mathrm{F}$ & 1,5 & 7,397 & 36,6 & 85,3 & 21,4 & $-1,7$ & 94,4 \\
\hline Tuti & Cocker & $\mathrm{F}$ & 7 & 7,403 & 34,6 & 90,8 & 20,8 & $-2,5$ & 96,1 \\
\hline Shena & SRD & $\mathrm{F}$ & 0,7 & 7,408 & 35,4 & 99,9 & 21,4 & $-1,8$ & 97,0 \\
\hline Lucky & Cocker & $\mathrm{M}$ & 9 & 7,410 & 34,6 & 99,8 & 21,4 & $-2,4$ & 97,7 \\
\hline Meg 1 & PA & $\mathrm{F}$ & 6,5 & 7,388 & 35,9 & 91,6 & 20,7 & $-2,7$ & 95,8 \\
\hline Meg 2 & Labrador & $\mathrm{F}$ & 3 & 7,438 & 31,8 & 98,0 & 20,5 & $-1,5$ & 96,8 \\
\hline Sophia & SRD & $\mathrm{F}$ & 0,8 & 7,402 & 32,9 & 91,7 & 19,5 & $-3,2$ & 95,6 \\
\hline Susie & SRD & $\mathrm{F}$ & 7 & 7,412 & 32,4 & 88,1 & 19,7 & $-2,9$ & 95,3 \\
\hline Mexerica & Golden & $\mathrm{F}$ & 0,8 & 7,433 & 32,7 & 93,9 & 20,9 & $-1,5$ & 96,5 \\
\hline Stephanie & Cocker & $\mathrm{F}$ & 8 & 7,450 & 35,3 & 85,5 & 23,6 & 0,9 & 96,0 \\
\hline Kika & SRD & $\mathrm{F}$ & 2 & 7,422 & 34,5 & 99,2 & 21,5 & $-1,3$ & 97,1 \\
\hline Mila & SRD & $\mathrm{F}$ & 5 & 7,421 & 38,8 & 85,0 & 24,3 & 0,7 & 95,6 \\
\hline sn & SRD & - & - & 7,417 & 37,7 & - & 23,4 & $-0,1$ & - \\
\hline sn & SRD & - & - & 7,379 & 38,5 & 90,4 & 21,7 & $-2,8$ & 95,4 \\
\hline sn & SRD & - & & 7,378 & 37,0 & 90,9 & 21,0 & $-3,0$ & 95,9 \\
\hline sn & SRD & - & - & 7,392 & 30,5 & 96,4 & 17,8 & $-5,1$ & 96,5 \\
\hline sn & SRD & - & - & 7,391 & 32,1 & 94,8 & 18,8 & $-4,5$ & 96,6 \\
\hline sn & SRD & - & - & 7,426 & 32,9 & 97,8 & 20,9 & $-2,0$ & 97,2 \\
\hline sn & SRD & - & - & 7,392 & 34,6 & 92,8 & 20,4 & $-3,3$ & 96,5 \\
\hline sn & SRD & - & - & 7,389 & 35,4 & 92,6 & 20,6 & $-3,1$ & 96,3 \\
\hline \multirow[t]{9}{*}{$\mathrm{sn}$} & SRD & - & - & 7,381 & 27,9 & 96,7 & & $-6,8$ & 96,3 \\
\hline & & & Média: & 7,418 & 33,4 & 95,7 & 21,1 & $-2,2$ & 96,5 \\
\hline & & & DP: & 0,026 & 3,8 & 8,3 & 2,2 & 1,7 & 1,0 \\
\hline & & & $\mathrm{a}+2 \cdot \mathrm{DP}$ & 7,470 & 41 & 112 & 25 & 1,0 & 99 \\
\hline & & & $\mathrm{a}-2 \cdot \mathrm{DP}$ & 7,370 & 26 & 79 & 17 & $-6,0$ & 95 \\
\hline & & & Mediana: & 7,417 & 35 & 95 & 21 & $-2,0$ & 97 \\
\hline & & Per & til 2,5\%: & 7,379 & 25 & 84 & 17 & $-5,3$ & 94 \\
\hline & & Perc & il $97,5 \%$ : & 7,472 & 39 & 114 & 25 & 1,0 & 98 \\
\hline & Teste & norm & lade $(P)^{*}$ & 0,926 & 0,356 & 0,728 & 0,348 & 0,896 & 0,886 \\
\hline
\end{tabular}

$\mathrm{PCO}_{2}$ : pressão parcial de dióxido de carbono; $\mathrm{PO}_{2}$ : pressão parcial de oxigênio; $\left[\mathrm{HCO}_{3}^{-}\right]$: concentração plasmática do bicarbonato; $\mathrm{BE}$ : déficit de base; $\mathrm{SO}_{2}$ saturação sangüínea de oxigênio; sn: sem nome.

*Teste de Kolmogorov-Smirnov 
APÊNDICE G - Valores da determinação dos eletrólitos plasmáticos e bioquímica sérica dos cães clinicamente hígidos incluídos no grupo controle.

\begin{tabular}{|c|c|c|c|c|c|c|c|c|c|c|c|c|}
\hline pront & nome & $\mathrm{Na}^{+}$ & $\mathbf{K}^{+}$ & $\mathrm{Ca}^{2+}$ & $\mathrm{Cl}^{-}$ & Mg & AG & Glu & Uréia & Crea & $\mathbf{P i}$ & $\beta$-НОВ \\
\hline 162704 & Cipo & 144,0 & 3,74 & 1,365 & 111,1 & 2,0 & 15,9 & 99 & 89 & 1,84 & 4,34 & - \\
\hline 164084 & Pituca & 145,8 & 4,09 & 1,246 & 106,5 & 2,5 & 19,2 & 92 & 34 & 1,12 & 4,43 & - \\
\hline 156098 & Paty & 142,6 & 3,82 & 1,328 & 111,0 & 2,3 & 7,2 & 83 & 40 & 1,07 & 4,39 & - \\
\hline 164435 & Astor & 143,3 & 4,38 & 1,292 & 111,7 & 1,9 & 17,8 & 74 & 36 & 1,27 & 3,76 & - \\
\hline 164099 & Lupy & 142,8 & 3,87 & 1,302 & 109,0 & 1,9 & 15,7 & 94 & 33 & 1,26 & 2,17 & - \\
\hline sn & Satine & 149,5 & 4,30 & 1,273 & 110,2 & 2,1 & 21,4 & 76 & 29 & 1,25 & 3,29 & - \\
\hline 162649 & Gull & 147,4 & 3,91 & 1,288 & 108,5 & 1,9 & 19,6 & 79 & 44 & 1,39 & 4,31 & - \\
\hline 164698 & Higor & 143,7 & 4,23 & 1,427 & 110,2 & 2,1 & 16,7 & 74 & 34 & 1,20 & 3,23 & - \\
\hline 157397 & Bob & 144,0 & 4,10 & 1,320 & 111,6 & 2,3 & 19,3 & 68 & 25 & 1,07 & 3,72 & - \\
\hline 164881 & Melissa & 143,8 & 3,65 & 1,441 & 109,3 & 1,8 & 17,1 & 96 & 47 & 1,16 & 6,6 & 0,06 \\
\hline 164912 & Atila & 142,6 & 4,37 & 1,338 & 108,9 & 1,9 & 17,4 & 81 & 30 & 1,36 & 3,32 & 0,07 \\
\hline 163889 & Melissia & 144,4 & 3,62 & 1,390 & 110,0 & 1,8 & 16,0 & 92 & 31 & 1,27 & 6,25 & 0,05 \\
\hline 163993 & Juca & 142,3 & 4,19 & 1,336 & 107,3 & 2,0 & 15,5 & 76 & 24 & 1,38 & 3,32 & 0,04 \\
\hline sn & Barney da K & 142,9 & 3,78 & 1,294 & 111,9 & 1,8 & 14,4 & 86 & 50 & 1,22 & 5,59 & 0,04 \\
\hline 137757 & Jane & 140,3 & 3,60 & 1,241 & 110,9 & 2,0 & 16,0 & 92 & 25 & 1,19 & 3,79 & 0,05 \\
\hline sn & Lola & 143,4 & 3,98 & 1,312 & 111,3 & 2,3 & 18,3 & 90 & 32 & 1,26 & 3,13 & 0,07 \\
\hline 154870 & Shaila & 142,9 & 3,81 & 1,366 & 110,8 & 2,1 & 14,5 & 106 & 28 & 1,65 & 3,99 & 0,05 \\
\hline 153995 & Tuti & 145,8 & 3,48 & 1,318 & 112,9 & 2,0 & 15,6 & 88 & 26 & 1,19 & 4,24 & 0,06 \\
\hline 164584 & Shena & 143,4 & 4,05 & 1,366 & 108,6 & 1,7 & 17,5 & 76 & 13 & 1,24 & 7,04 & 0,05 \\
\hline sn & Lucky & 150,6 & 4,38 & 1,200 & 116,7 & 2, & 16,9 & 88 & 45 & 1,33 & 3,82 & 0,07 \\
\hline 164793 & Meg da K & 141,9 & 4,02 & 1,251 & 113,8 & 1,9 & 11,4 & 83 & 19 & 1,25 & 3,74 & 0,17 \\
\hline 3560 & Meg 2 & 146,6 & 3,58 & 1,286 & 113,0 & 2,1 & 16,7 & 110 & 28 & 1,64 & 2,70 & 0,05 \\
\hline 3559 & Sophia & 142,2 & 3,78 & 1,346 & 113,5 & 2,0 & 13,0 & 108 & 43 & 1,51 & 5,60 & 0,06 \\
\hline 3558 & Susie & 145,0 & 4,32 & 1,338 & 114,0 & 2,1 & 15,6 & 88 & 45 & 1,65 & 3,86 & 0,06 \\
\hline 3557 & Mexerica & 144,5 & 3,45 & 1,411 & 109,9 & 1,9 & 17,2 & 128 & 37 & 1,21 & 7,17 & - \\
\hline 3555 & Stephanie & 146,4 & 4,23 & 1,334 & 109,6 & 2,1 & 17,4 & 92 & 31 & 1,13 & 4,51 & 0,06 \\
\hline 11 & Kika & 144,8 & 3,93 & 1,403 & 110,5 & 2,1 & 16,7 & 90 & 41 & 1,25 & 5,86 & 0,06 \\
\hline 12 & Mila & 143,0 & 4,60 & 1,355 & 109,9 & 1,8 & 13,4 & 83 & 41 & 1,35 & 4,85 & 0,04 \\
\hline 1 & sn & 143,2 & 4,36 & 1,377 & 107,6 & 2,3 & 16,5 & 117 & 45 & 1,49 & 5,56 & - \\
\hline 2 & sn & 146,6 & 3,83 & 1,388 & 108,4 & 2,3 & 20,3 & 109 & 44 & 1,59 & 4,07 & - \\
\hline 8 & sn & 142,5 & 4,74 & 1,438 & 108,0 & 2,0 & 18,2 & 115 & 60 & 1,58 & 7,89 & - \\
\hline 7 & sn & 142,8 & 4,02 & 1,419 & 108,4 & 1,9 & 20,6 & 105 & 44 & 1,77 & 5,09 & - \\
\hline 10 & sn & 145,0 & 3,91 & 1,458 & 107,3 & 1,9 & 22,9 & 114 & 33 & 1,48 & 4,33 & - \\
\hline 5 & sn & 145,3 & 4,20 & 1,345 & 107,4 & 2,2 & 21,2 & 106 & 44 & 1,33 & 6,25 & - \\
\hline 9 & sn & 142,8 & 3,85 & 1,434 & 106,8 & 2,0 & 19,4 & 112 & 31 & 1,34 & 4,74 & - \\
\hline 3 & sn & 149,4 & 4,23 & 1,451 & 111,2 & 2,6 & 21,8 & 112 & 40 & 1,32 & 6,49 & - \\
\hline \multirow[t]{9}{*}{4} & sn & 150,6 & 4,00 & 1,426 & 111,3 & 2,0 & 27,4 & 110 & 46 & 1,34 & 5,24 & - \\
\hline & Média: & 145 & 4,0 & 1,349 & 110 & 2,0 & 17 & 94 & 38 & 1,35 & 4,67 & 0,1 \\
\hline & DP: & 2,5 & 0,3 & 0,1 & 2,3 & 0,2 & 3,5 & 15 & 13 & 0,19 & 1,34 & 0,0 \\
\hline & Média + 2.DP: & 149 & 4,6 & 1,48 & 115 & 2,4 & 24 & 124 & 63 & 1,73 & 7,30 & 0,12 \\
\hline & Média - 2.DP: & 140 & 3,4 & 1,22 & 106 & 1,7 & 11 & 65 & 12 & 0,97 & 2,03 & 0,01 \\
\hline & Mediana & 144 & 4,0 & 1,35 & 110 & 2 & 17 & 91,90 & 36 & 1,320 & 4,3 & 0,06 \\
\hline & entil 2,5\%: & 142 & 3,5 & 1,24 & 107 & 1,8 & 11 & 73 & 19 & 1,07 & 2,6 & 0,04 \\
\hline & rcentil 97,5\%: & 151 & 4,6 & 1,45 & 114 & 2,5 & 23 & 118 & 62 & 1,78 & 7,2 & 0,13 \\
\hline & malidade $(P)^{*}$ & 0,014 & 0,989 & 0,983 & 0,973 & 0,254 & 0,056 & 0,519 & 0,355 & 0,200 & 0,424 & 0,0001 \\
\hline
\end{tabular}

$\mathrm{Na}^{+}$: sódio plasmático; $\mathrm{K}^{+}$: potássio plasmático; $\mathrm{Ca}^{2+}$ : cálcio ionizado plasmático; $\mathrm{Cl}^{-}$: Cloro plasmático; $\mathrm{Mg}$ : magnésio total sérico; AG: anion gap; Gli: glicemia; Uréia: uréia sérica; Crea: creatinina sérica; Pi: fósforo inorgânico sérico; $\beta$-HOB: $\beta$-hidroxibutirato sérico; sn: sem nome.

*Teste de Kolmogorov-Smirnov 